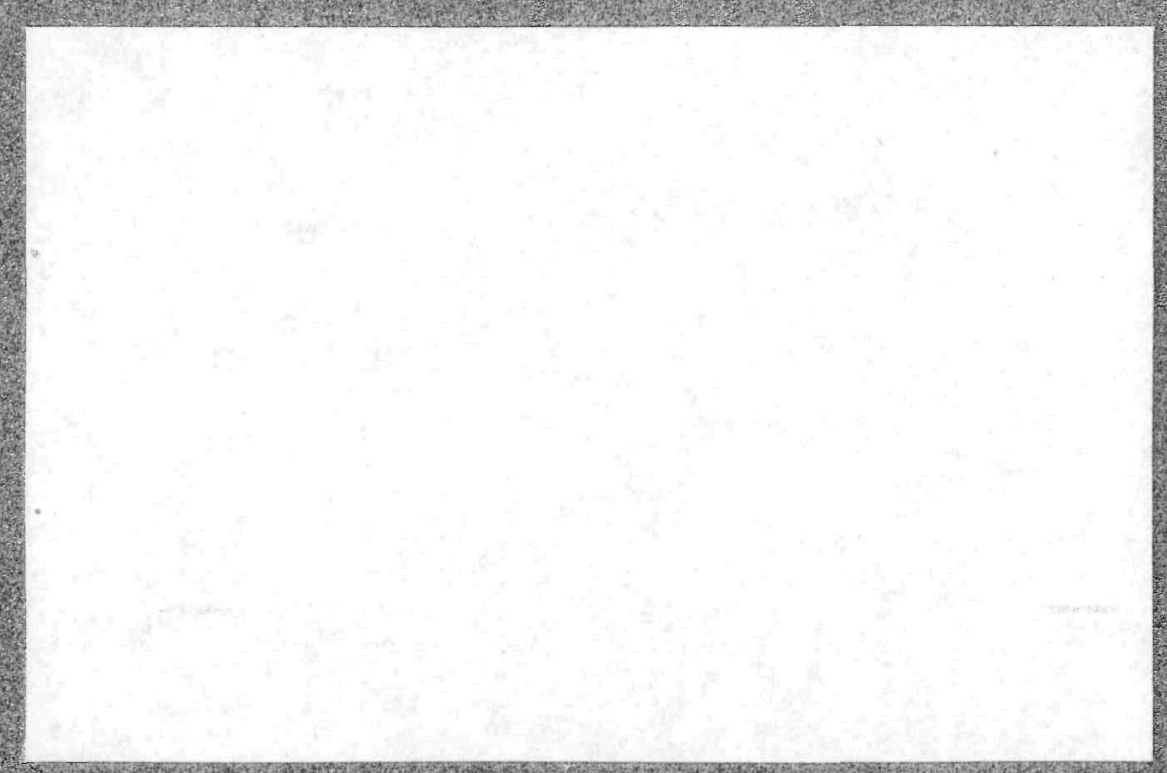




\section{DISCLAIMER}

This report was prepared as an account of work sponsored by an agency of the United States Government. Neither the United States Government nor any agency Thereof, nor any of their employees, makes any warranty, express or implied, or assumes any legal liability or responsibility for the accuracy, completeness, or usefulness of any information, apparatus, product, or process disclosed, or represents that its use would not infringe privately owned rights. Reference herein to any specific commercial product, process, or service by trade name, trademark, manufacturer, or otherwise does not necessarily constitute or imply its endorsement, recommendation, or favoring by the United States Government or any agency thereof. The views and opinions of authors expressed herein do not necessarily state or reflect those of the United States Government or any agency thereof. 


\section{DISCLAIMER}

Portions of this document may be illegible in electronic image products. Images are produced from the best available original document. 


\title{
CFSI PICES
}

H. $\$ 300 ; \mathrm{MN} .65$

REIEASED EOR ANNWXEUENT

IN NUCIEAR SCIEUCE AESTRACTS

\author{
SNAP 19 \\ TEST REPORT \\ THERMAL PERFORMANCE OF MATERIALS \\ AND MECHANICAL JOINTS
}

MND-3607-112

November 1966

\section{LEGAL NOTICE}

This report was prepared as an account of Government sponsored work. Nelther the United States, nor the Commission, nor any person acting on behalf of the Commission:

,

A. Makes any warranty or representa information contaned in this report, or that the use racy, completeness, or usefulness of the or process disclosed in this report may not infringe privately o mned rights; or

thately omned righis; or B. Assumes any labilities with respect to the use of, or for damages result

use of any information, apparatus, method, or process of the Commssion" includes any em-

As used in the above, "person actung on behall of the Commssactor, to the extent that ployee or contractor of the commission, or employee of such contrach contractor prepares, such employee or contractor of the Commission, or employee of such contoyment or contract disseminates, or provides access to, any information pursuant

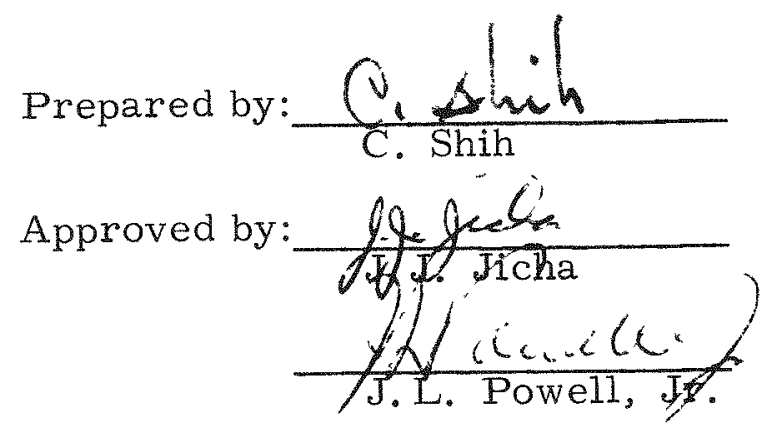




\section{LEGAL NOTICE}

This report was prepared as an account of Government sponsored work. Neither the United States, nor the Commission, nor any person acting on behalf of the Commission:

A. Makes any warranty or representation, expressed or implied with respect to the accuracy, completeness, or usefulness of the information contained in this report, or that the use of any information, apparatus, method, or process disclosed in this report may not infringe privately owned rights; or

B. Assumes any liabilities with respect to the use of, or for damages resulting from the use of any information, apparatus, method, or process disclosed in this report.

As used in the above, "person acting on behalf of the Commission" includes any employee or contractor of the Commission, or employee of such contractor, to the extent that such employee or contractor of the Commission, or employee of such contractor prepares, disseminates, or provides access to, any information pursuant to his employment or contract with the Commission, or his employment with such contractor. 


\section{FOREWORD}

This test report is submitted by the Martin Company, Baltimore, Maryland, a division of the Martin Marietta Corporation, in support of United States Atomic Energy Commission Contract AT(30-1)-3607, Item (4) (1) (h), of the SNAP 19 Experimental Program.

\section{ACKNOWLEDGMENT}

The experimental work was conducted by J. Grim of the Thermodynamics Laboratory and by J. Suhorsky of the Materials Engineering Laboratories. W. Davidson made the mechanical design of the test fixtures and the specimens. Special gratitude is expressed to A. Haron for his effort in analyzing the test results and the various valuable suggestions during the program. 
Blank 


\section{CONTENTS}

Legal Notice . ..................

Page

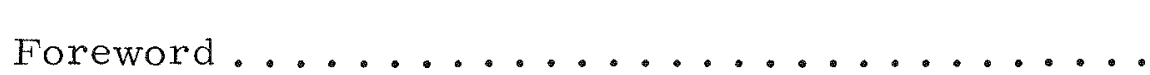

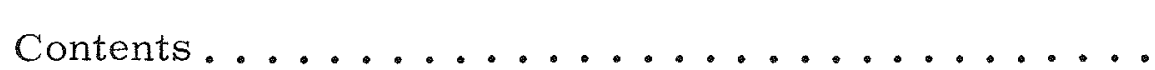

Summary $\ldots \ldots \ldots \ldots \ldots \ldots \ldots$

Symbols and Definitions $\ldots \ldots \ldots \ldots \ldots \ldots$ ix

I. Introduction $\ldots \ldots \ldots \ldots \ldots \ldots \ldots \ldots \ldots \ldots$

II. Technical Discussion ................. 3

A. Joint Thermal Contact Conductance......... 3

B. Material Properties ............... 5

III. Test Program ...................... 7

A. Joint Thermal Conductance Test.......... 7

B. Thermal and Mechanical Properties of ZH62A

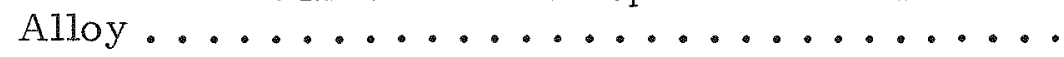

IV. Discussion of Results ................ 33

A. Joint Thermal Contact Conductance......... 33

B. Material Properties Measurements......... 41

V. Conclusion and Recommendations . . . . . . . . . . 43

A. Recommendations ............... 43

VI. References.......................... 45 
Blank 


\section{SUMMARY}

The purpose of this program was to provide basic information on the thermal contact conductance of mechanical joints for application to Nimbus B/SNAP 19 thermal analysis and to gain knowledge of the proper joint thermal conductance in scaled thermal models. A secondary objective was to evaluate material properties such as the coefficient of thermal expansion, thermal conductivity, emissivity, specific heat, and tensile and creep strengths at temperatures from $300^{\circ}$ to $783^{\circ} \mathrm{K}$. No such information at temperatures above $400^{\circ} \mathrm{K}$ is available in the Iiterature.

For the joint conductance study, three specimens of ZH62A Mg alloy against 2024-T5Al alloy, the same materials as those used on Nimbus B spacecraft, were fabricated. One used a hexagonal-head bolt, one a countersunk head bolt and one a rivet as fasteners. All three specimens were of approximately the same size as the prototype. Thermal conductances were evaluated at four different temperatures ranging from $340^{\circ}$ to $566^{\circ} \mathrm{K}$ for each load and environment pressure.

For thermal scaling of joint thermal conductance, two more specimens of stainless steel were fabricated, one approximately the same size as those used on the Nimbus B spacecraft and the other a half-scale model. The steel specimens were tested under environmental conditions identical to those experienced by the $\mathrm{Mg}-\mathrm{Al}$ specimens.

Contact thermal conductances of joints, typical of those used on the Nimbus B spacecraft, were measured at various temperatures, both with and without a special grease between the surfaces of contact. The measured thermal conductances of all joints with grease coated surfaces are higher by almost an order of magnitude than the minimum value given by General Electric specifications. One of the specimens tested showed some characteristics not common to all the rest, possibly due to inaccuracy as a result of the small temperature drop across the joint under greased conditions. Thermal scaling of mechanical joints was proven to be quite feasible within the scope of interest to the Thermal Scale Model Program (Task 4.1.a). Using the thermal scaling criteria given in Ref. 1, scaling of material properties was within $11 \%$ at all temperatures tested. With respect to scaling to size, the experimental results agree with the criterion within $18 \%$. The agreement of experimental results with criterion for scaling of a greased joint is about $23 \%$. For thermal conductance of mechanical joints with a grease interface, a tolerance of $50 \%$ is recommended for thermal design purposes, due to uncertainties about the effects of temperature, pressure and time of exposure in vacuum on the thickness and density of the grease. 
Material properties at various temperatures were determined following ASTMI standard procedures. There was some uncertainty about the thermal conductivity and creep strength at temperatures close to the melting point. Verification tests of thermal conductivity of ZH62A were simultaneously carried out at both the Nuclear Research Laboratory and the Thermodynamics Laboratory. Some scattering of test results was noted around $770^{\circ} \mathrm{K}$. Values in the temperature region from $740^{\circ} \mathrm{K}$ up should be used with caution.

Recommendations were made to investigate anomalies in the creep strength data and to supplement the data obtained on thermal conductance of mechanical joints.

Tests of typical properties at elevated temperatures are summarized

Property

Thermal Conductivity $\left(\mathrm{cal} / \mathrm{cm}^{2}-\sec -\left({ }^{\circ} \mathrm{K} / \mathrm{cm}\right)\right)$

Specific Heat

(cal/gm- ${ }^{\circ} \mathrm{K}$ )

Coefficient of Expansion

(micro-cm $/ \mathrm{cm}^{\circ}{ }^{\circ} \mathrm{K}$ )

Total Hemispherical Emittance

Total Normal Emittance

Tensile Strength $\left(\mathrm{Kg} / \mathrm{cm}^{2}\right)$

Yield

$2510 \quad 935$

300

Temperature $\left({ }^{\circ} \mathrm{K}\right)$

$554 \quad \underline{610} \quad \underline{672} \quad \underline{700}$
0.33
0.285
0.265
0.258

\subsection{1}

0.318

0.335

$23 \quad 29$

29.

29.5

29.5

0.111

0.116

0.80

0.90

$1554 \quad 618$

680

422

317

571

260 


\section{SYMBOLS AND DEFINITIONS}

$a$

A

b

d

E

$h_{i j}$

$\mathrm{H}$

K

L

$P_{\text {a }}$

$\mathrm{R}$

$\mathrm{S}$

$\mathrm{T}$

q

radius of microscopic contact area (meter)

surface area (meter $\left.{ }^{2}\right)$

radius of macroscopic contact area (meter)

thickness (meter)

modulus of elasticity (Newton/meter ${ }^{2}$ )

thermal contact conductance (joule $/$ meter $^{2}-\mathrm{sec}^{-0} \mathrm{~K}$ )

microhardness of material (Newton $/$ meter $^{2}$ )

thermal conductivity (joule/( meter $^{2}-\sec ^{-0} \mathrm{~K} /$ meter $)$ )

linear dimensions (meter)

pressure over apparent contact surface area (Newton $/$ meter ${ }^{2}$ )

contact thermal resistance $\left(\mathrm{sec}^{-0} \mathrm{~K} /\right.$ joule)

peak to valley surface deviation (meter)

temperature $\left({ }^{\circ} \mathrm{K}\right)$

rate of heat transfer (joule/sec)

Subscripts

$i, j \quad$ quantities associated with surfaces in contact with $A_{i}$ and $\mathrm{A}_{j}$, respectively

m, p quantities associated with the model and the prototype, respectively

t total value

mi, ma quantities associated with microscopic and macroscopic phenomena, respectively 


\section{INTRODUCTION}

The thermal performance of a spacecraft in re-entry depends a great deal on the thermal conductance through various mechanical joints. In some instances a joint must be designed for maximum thermal resistance to prevent heat leakage such as in cryogenic storage. In other applications, the joint has to be designed for minimum thermal resistance so that the heat dissipation from certain areas can be facilitated. To our best knowledge, the work done on contact thermal conductance has been limited to the measurement of conductance between plane surfaces under given temperature conditions and surface finishes. No work on scaling of thermal conductance has been reported. In order to have a good representative thermal model of the Nimbus B vehicle, it is essential that a good knowledge of the thermal conductance of mechanical joints used in the spacecraft be obtained.

There is also a lack of knowledge of the general thermal and mechanical properties of magnesium or magnesium thorium alloy at temperatures near the melting point.

The objective of this program is to evaluate the thermal contact conductance of mechanical joints typical of those in the Nimbus $B$ satellite sensory ring and to determine some of the physical and thermal properties of magnesium alloy $\mathrm{ZH} 62 \mathrm{~A}$ at higher temperatures. These are not available in the literature. To effectively attain these goals, the program was divided into two subtasks: the joint thermal contact conductance study carried out by the Thermodynamics Laboratory and the material properties study carried out by the Materials Engineering Laboratories.

Five specimens were fabricated and tested in the joint thermal contact conductance study. Three of the specimens, one each with a hexagonal-head bolt fastener, countersunk machine screw fastener and riveted fastener, were made with $\mathrm{ZH} 62 \mathrm{~A}$ and Al 2024-T 4 forming the mating surfaces. A construction typical of that used in the Nimbus $B$ sensory ring assembly was employed. A fourth specimen was made with Type 304 stainless steel forming the mating surfaces for thermal scaling when changing materials. A fifth specimen which was a reduced scale of the fourth specimen was used for thermal scaling in size. The contact conductances of the joints were measured at temperatures from $340^{\circ}$ to $540^{\circ} \mathrm{K}$. Both precleaned mating surfaces and surfaces coated with special thermal grease according to General Electric specifications were used.

Material properties studied in this program included: (1) emittance, (2) thermal conductivity, (3) specific heat, (4) creep strength, (5) tensile strength, and (6) thermal expansion. 
At the start of the program, an analytical investigation of the influence of thermal strain on joint conductance was made. The purpose was to find out whether distortion due to thermal expansion would change the contact pressure around the fastener, thus affecting the contact thermal conductance characteristics. The design of experimental apparatus would also have to take into account any such deviations in order to obtain realistic information. Analysis showed that no such correction was necessary.

Details of the technical approach, conducting the test program, the test results and their interpretations are contained in the following sections of this report. 


\section{TECHAICAL DISCUSSION}

\section{A. JOINT THERMAL CONTACT CONDUCTANCE}

A major obstacle in theoretical analysis of the thermal performance of a spacecraft or the experimental modeling of such has been the lack of knowledge of thermal contact conductance of mechanical joints having an interface between the surfaces of contact. The resistance to heat flow through a mechanical joint depends on a number of parameters such as the thermal conductivity and the hardness of the materials, the surface conditions in both microscopic and macroscopic ways, the environment, the properties of the medium between the surfaces, the pressure, the way the surfaces are held together and the heat flux through the joint. In a bolted joint, it is further complicated by the uncertainty about the pressure produced by tor quing.

Every one of these parameters will have to be dealt with in a general treatment. To meet the objective of this program, however, a number of simplifications can be applied to facilitate the study. The surface conditions can be closely matched by using the same machine finish as was used on the prototype, by using identical materials and fastening devices, and by applying the identical torques used on the prototype. In other words, a theoretically identical joint was made for the study.

For application to the thermal scale-model experiment (Task 4,1,a), the conditions were changed from those of the thermal contact conductance evaluation. To meet the criteria on thermal scaling with model temperatures the same as the prototype temperatures at homologous points, a material with a thermal conductivity different from that of the prototype has to be used for the model (Ref. 1). The area of contact is reduced in scale and different material properties are involved. One theoretically simple way, but difficult practically, is to make a scaled-down joint of the desired material and fastener, using some reproducible technique which will give the model the same thermal conductance as the prototype. Gabron, et al., used the first approach in the half-scale Mariner-Mars satellite modeling (Ref. 2). Another way is to establish a valid scaling law and then use this law to design the reduced model. This second approach was used in this program because of the difficulties involved in instrumenting and measuring thermal performance of extremely small scaled models.

Heat transfer through the metallic joint consisted of:

(1) Conduction through metallic contacts between the two surfaces 
(2) Convection through fluid left between cavities on both surfaces

(3) Radiation.

For space applications where the environment is practically a vacuum, convection by fluid is extremely small. It was found that below a pressure of 10 microns of mercury, the convective contribution to contact thermal conductance is negligible (Ref. 3). This was also confirmed in this investigation. Since the temperature difference across the interface is not large, generally from fractions of a degree to a few degrees Kelvin, radiation heat transfer is also negligible. Thus, the only heat transfer mode to be considered in this case is the conduction through metallic contacts.

Contact thermal conductance of a mechanical joint in a vacuum environment with no intermedjate medium consists of metallic conduction through numerous microscopic high spots if the surfaces are perfectly plane. For ordinary plane surfaces, there exists macroscopic irregularities or waviness which prevents the portions of the microscopic high spots from contacting the other surface. Each of these two phenomena has to be treated independently. If the surfaces in contact are reasonably flat, the microscopic phenomenon may be the predominant one. If the surfaces are rough and wavy, such as unmachined surfaces, it may be the other way around. Most treatise on this subject have been confined to the microscopic phenomenon. The macroscopic phenomenon was treated by Clausing and Chao (Ref. 3) in a doctoral dissertation at the University of Illinois.

An analytical treatise made by Hultberg (Ref. 4) assumed a linearly decreasing distribution function, from the center toward the periphery, of the thermal conductance of a bolted joint. The relation is represented by the equation

$$
\left[\bar{h}=h_{o} 1-c\left(\frac{r}{a}\right)\right]
$$

where $h_{0}$ is the maximum conductance at the edge of the bolt, a the outer radius of the joint, $r$ the radius and $c$ the slope of the linear variation. This approach sounds reasonable for rigid plane surfaces with microscopic thermal constriction dominating. In a more rigorous treatise of metallic plates held together by a bolt, each side of the joint may be considered as a prismatic beam with a concentrated load resting on an elastic foundation. Thus, the deflection of the plate at distance $x$ from the load application point may be given as (Ref. 5):

$$
y=\frac{F \beta}{2 k} e^{-\beta x}(\cos \beta x+\sin \beta x)
$$


where

$$
k=\frac{E I}{y} \frac{d^{4} y}{d x^{4}}, \quad \beta=4 \sqrt{\frac{K}{4 E I}}
$$

and $F$ is the clamping or bolting load, $E$ the modulus of elasticity, and I the moment of inertia of the plate section. Equation 2 assumes a wave form with gradually decreasing amplitude and becomes negative a certain distance from the center. This solution would partially justify the results of an experimental investigation by Aron (Ref. 6). In Aron's experiment, it was found that the contact pressure varies from a minimum at the bolt hole edge to a maximum between the bolt head and the nut. The maximum pressure then declines to zero at a distance (from the edges of the bolt head and nut) of 1.7 times the thickness of the individual sheets of metal being held together. Beyond this radius, the two sheets of metal tend to separate by a microscopic amount.

Experimental investigation of thermal conductance of bolted joints has been done by investigators at Douglas Aircraft Company (Ref. 7), Arthur D. Little Company (Ref. 2) and others. Most of these were measurements of thermal conductances of given design and under given conditions. Scaling of thermal conductance of bolted joints has been tried by Gabron, et al. (Ref. 2). To the best of our knowledge, no published reports about experimental thermal scaling of bolted joints are available at present.

\section{B. MATERIAL PROPERTIES}

The thermal and mechanical properties of alloy ZH62A at room temperatures are listed in the Metals Handbook. For information of material properties at temperatures close to the melting point, about $630^{\circ} \mathrm{K}$, practically nothing is available. This is partly because this alloy is generally used in the low or medium temperature range up to $450^{\circ} \mathrm{K}$ and partly because the measurement of properties in the higher temperature range is very difficult. The accuracy in the temperature range close to its melting point is very inferior to that at lower temperatures due to the possible change of phase or state of portions of the alloy. Information about these materials will be required for thermal and dynamical analyses. 
Blank 


\section{TEST PROGRAM}

\section{A. JOINT THERMAL CONDUCTANCE TEST}

\section{Test Facility}

The test facility used consisted of a spherical vacuum chamber equipped with mechanical and diffusion pumping systems. Accurate thermocouple readout was made using a Minneapolis Honeywell Model 2745 potentiometer referenced to an ice bath in conjunction with a selector switch made especially for thermocouple applications. Power for heating the test specimen was provided by a Model RVC 36-5M d-c power supply whose output voltage regulation under load is $0.01 \%$. A multiple range $d^{-c}$ voltmeter plus a $50^{-} \mathrm{mv}$ meter connected across a five-ampere shunt was used to measure the electrical input to the specimen heating element. A picture of this setup can be seen in Fig. 1.

\section{Test Models}

Five joint specimens were tested. Three were representative of typical joint configurations existing in the structure of the Nimbus $B$ satellite. They were made in two halves which were bolted or riveted together. Three of these were full size with the halves made of different metals, namely 2024-T4 aluminum and ZH62A magnesium. The other two were made of 304 CRES, one full size and the other half size for the thermal scaling study. The mating surfaces of all specimens were carefully machined to the same surface roughness or finish in an effort to duplicate that which exists in the actual vehicle. This finish was No. 125 as designated by the GE specification. These specimens, fully instrumented, are pictured in Fig. 2.

Heat meters made of round bars of Armco iron were used, one on each side of the test specimen. The input meter made of one-inch diameter stock had an electric cartridge heater brazed into one end and the other end threaded to receive the test specimen. In between, three calibrated thermocouples were installed in locations exactly one inch apart as measured along the longitudinal axis. The output meter made of half-inch stock had one end welded into a water-cooled heat sink and the other end threaded for attachment to the test specimen. It also contained three calibrated thermocouples installed in a like manner. The construction and use of these heat meters are clearly illustrated in Fig. 3.

\section{Instrumentation}

Each specimen was instrumented with chromel-alumel thermocouples. Except for Specimen 4, the following procedure was used 


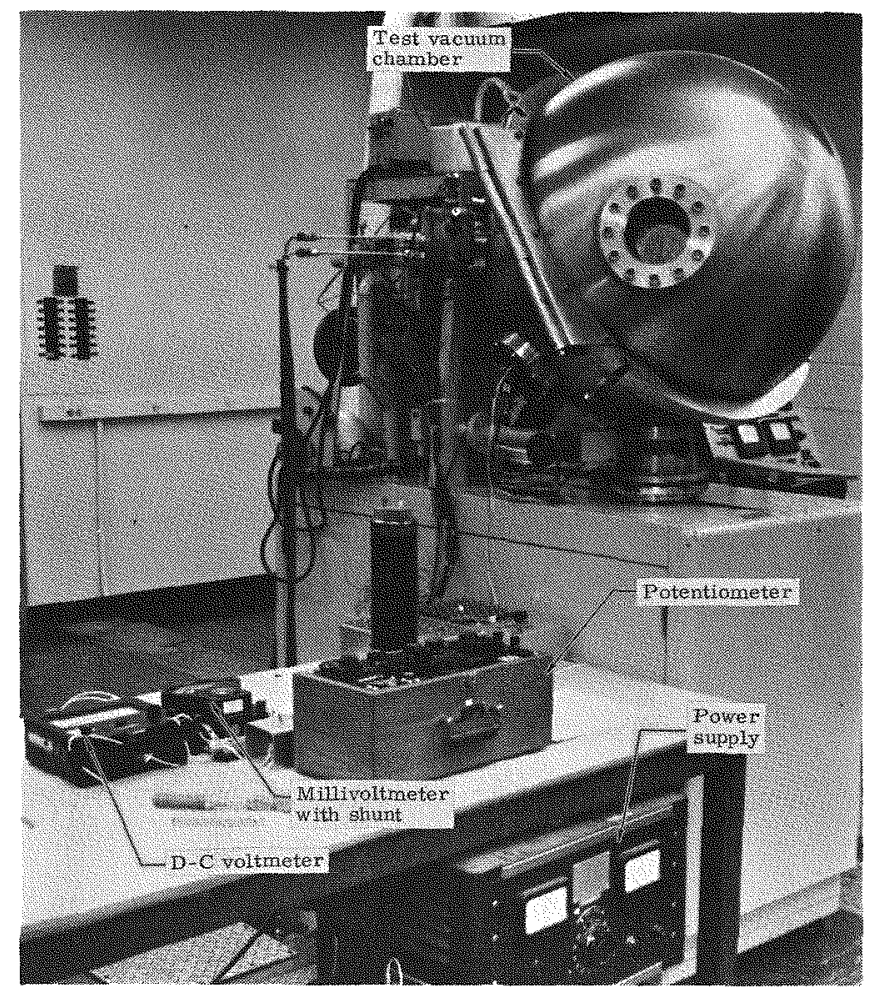

Fig. 1. Joint Thermal Conductance Test Equipment

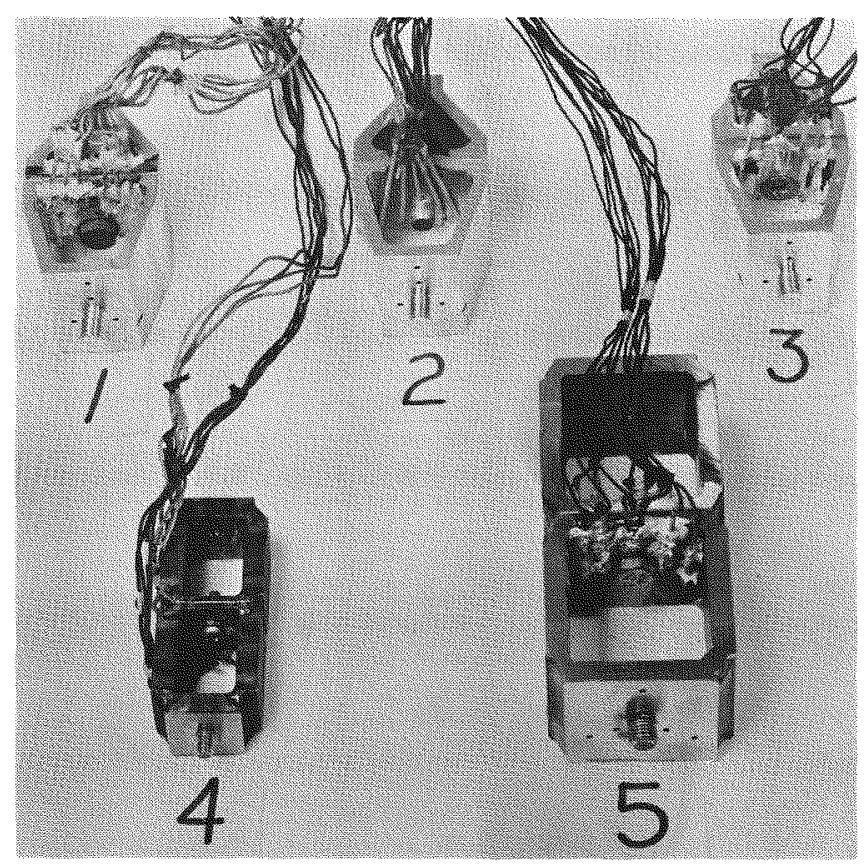

Fig. 2. Joint Thermal Conductance Test Specimens

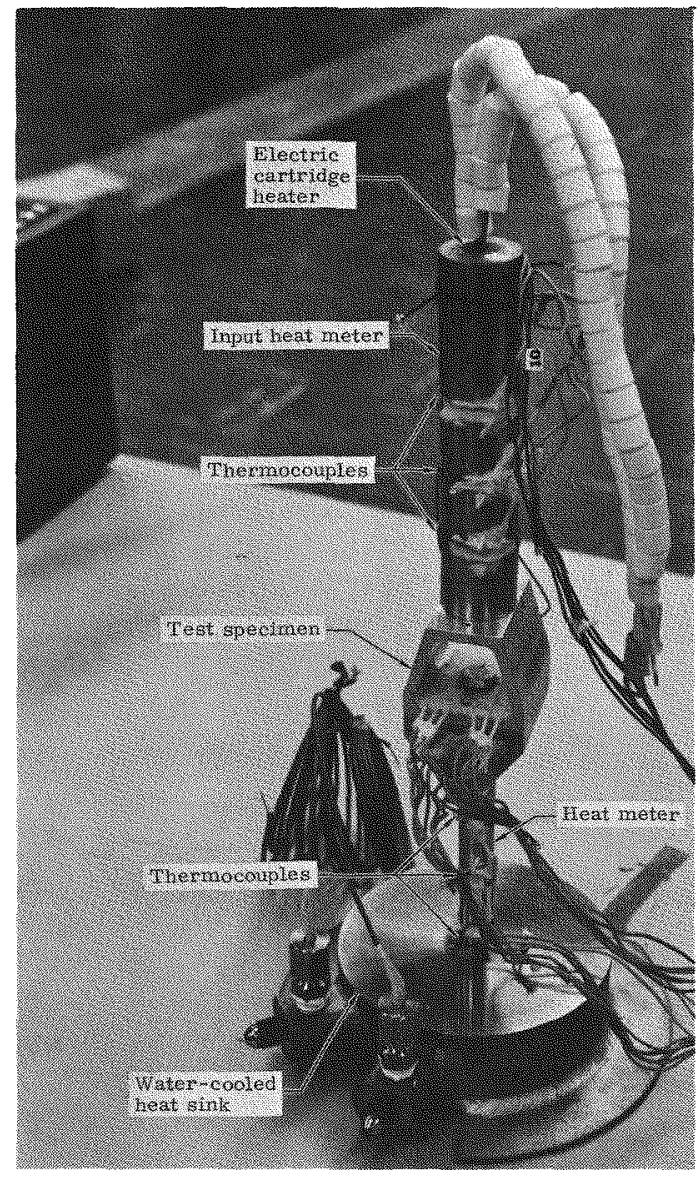

Fig. 3. Test Specimen and Heat Meters on Test Fixture 
for thermocouple installation. Holes $(1.58 \mathrm{~mm}$ in diameter) were drilled from the opposite side to a distance of $0.50 \mathrm{~mm}$ from the mating surfaces. These holes fell directly opposite one another in each half of the specimen. Sections of two-hole ceramic insulating tube strung on the wire back of the junction were made slightly shorter than the depth of the hole. With this tube held tightly in the hole, the edge was peened over, thus causing the thermocouple junction to be held firmly against the metal at the bottom of the hole. Short pieces of ceramic tube, held in place with dabs of Saueriesen 31, were used for electrical insulation to avoid the possibility of the teflon coating on the wire breaking down at higher temperatures and shorting out the thermocouple. In the case of Specimen 4, the thermocouples were simply spot welded in place on the side opposite the mating surfaces. The number of thermocouples, their exact location plus details of the peening operation are more fully explained by Fig. 4. Installation of the thermocouples in the Armco iron heat meters was done in the same manner but at a uniform hole depth of $6.35 \mathrm{~mm}$.

The thermocouples installed in both heat meters and Specimens 1 and 5 were calibrated before installation. Those in Specimens 2, 3 and 4 , though not calibrated, were fabricated in the same manner and from the same spool of premium grade wire as the others.

\section{Test Procedure}

A series of 52 tests considering the following variables was completed.

(1) Joint temperatures ranging from $340^{\circ}$ to $566^{\circ} \mathrm{K}$

(2) Type of metals comprising the joint

(3) Type of fastening: whether hexagonal head, countersunk bolt or riveted

(4) Difference in bolt torque

(5) With or without heat-conducting grease between the mating surfaces

(6) Change in chamber pressure.

A listing of all the test runs made, classified according to the se variables, is given in Table 1. A silicon grease-silver powder mixture made in accordance with General Electric Specification 171A4157 was used in the joint and was so noted. Prior to assembly of the specimen halves, all surfaces, particularly the mating surfaces, were thor oughly cleaned and rinsed with acetone. The halves were then 


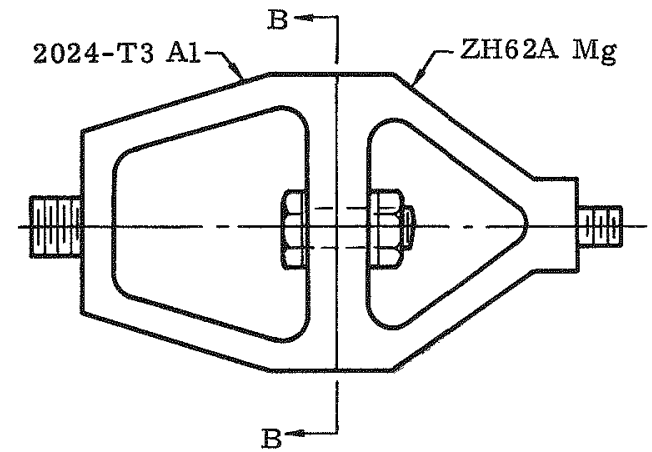

Typical Specimens Nos, 1 to 3

(A1--ZH62A)

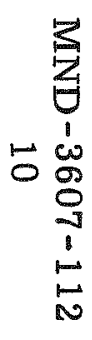

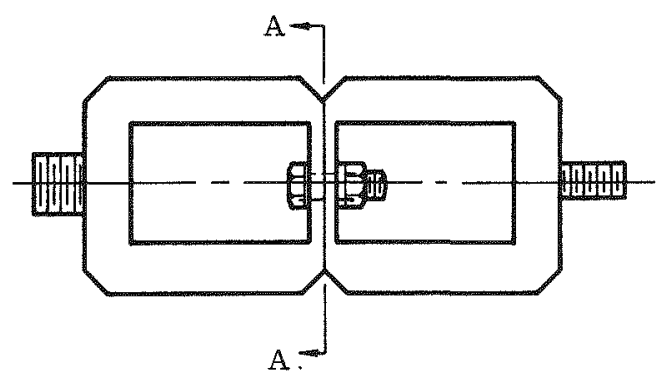

Specimen No. 4 (304 CRES)
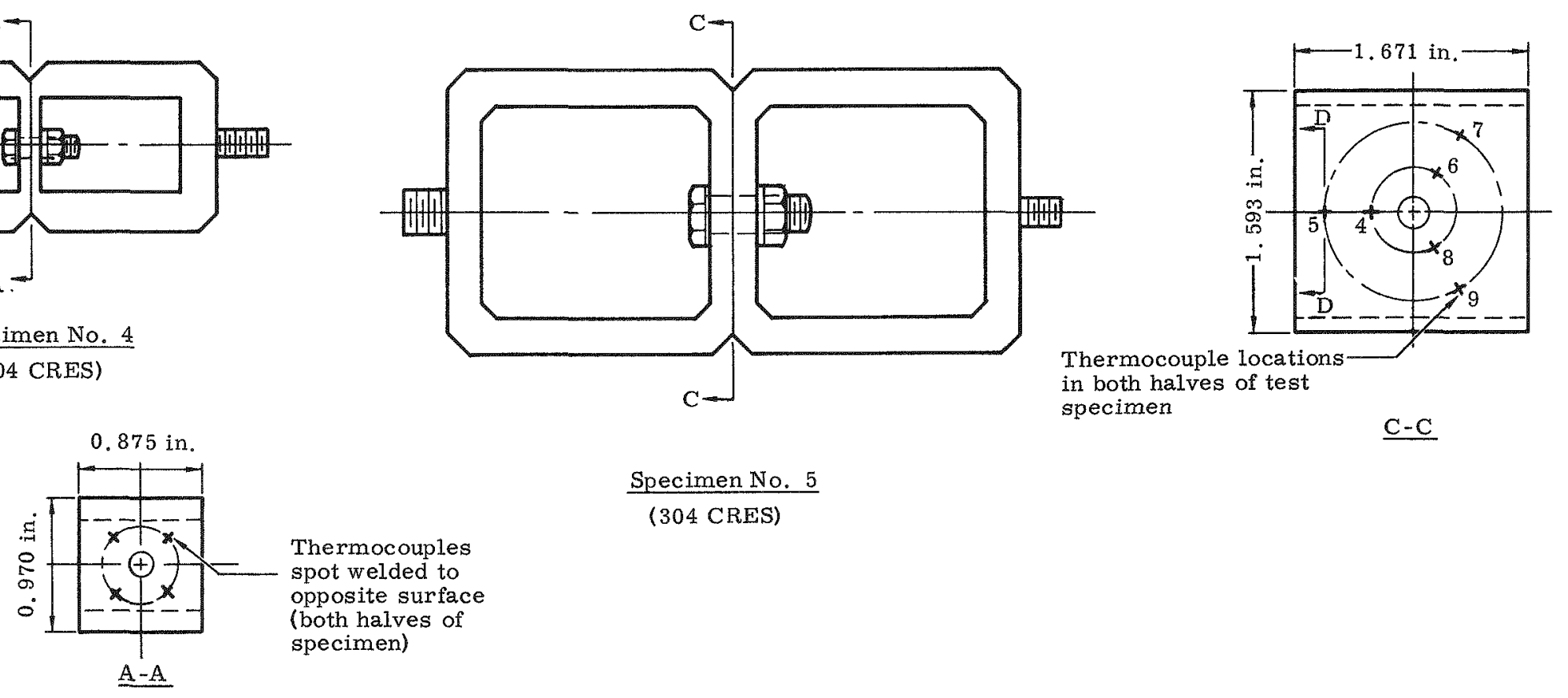

Specimen No. 5

(304 CRES)

\section{D-D}

$\underline{D^{\prime}-D^{\prime}}$

Fig. 4. Joint Conductance Specimens showing Thermocouple Locations 
TABLE 1

Test Data $\left({ }^{\circ} \mathrm{F}\right)$ from Thermocouples

\begin{tabular}{|c|c|c|c|c|c|c|c|c|c|c|c|c|c|c|c|c|c|c|c|}
\hline \multirow{2}{*}{$\begin{array}{l}\text { Test } \\
\text { No. }\end{array}$} & \multirow{2}{*}{$\begin{array}{l}\text { Spec } \\
\text { No. }\end{array}$} & \multicolumn{3}{|c|}{ Input Heat Meter } & \multicolumn{6}{|c|}{ Hot Half of Specimen } & \multicolumn{6}{|c|}{ Cold Half of Specimen } & \multicolumn{3}{|c|}{ Output Heat Meter } \\
\hline & & 1 & 2 & 3 & $* 4$ & 5 & 6 & 7 & 8 & 9 & *10 & 11 & 12 & 13 & 14 & 15 & 16 & 17 & 18 \\
\hline 1 & 1 & 714.0 & 670 & 622.5 & 531.9 & 534.1 & 531.89 & 537.87 & 530.35 & 537.62 & 521.3 & 520.63 & 527.1 & 518.14 & 527.13 & NG & & & \\
\hline 2 & 1 & 463.33 & 439.05 & 415.91 & 340.01 & 342.2 & 340.2 & 340.07 & 340.05 & 344.21 & 331.14 & 335.4 & 338.37 & 331.38 & 332.82 & NG & 271.71 & 200.16 & 134.4 \\
\hline 3 & 1 & 323.14 & 308.57 & 294.32 & 245.49 & 247.20 & 245.98 & 249.36 & 246.11 & 249.43 & 242.18 & 243.84 & 245.57 & 241.06 & 244.90 & NG & 203.3 & 156.5 & 113.2 \\
\hline 4 & 1 & 182.7 & 177 & 172 & 151 & 150.8 & 150.8 & 152.2 & 150.9 & 152.2 & 149.1 & 149 & 150 & 149.1 & 149 & NG & 129.9 & 110.9 & 92.3 \\
\hline 5 & 1 & 177 & 171.8 & 166.2 & 144.5 & 145 & 145.7 & 146.9 & 145.1 & 146.2 & 142.3 & 142.8 & 143.7 & 141.5 & 142.3 & $N G$ & 123 & 104.2 & 85.1 \\
\hline 6 & 1 & 330.51 & 315.57 & 300.85 & 248.40 & 250.28 & 248.8 & 252.41 & 248.71 & 251.88 & 240.26 & 245.78 & 247.76 & 242.23 & 246.71 & $\mathrm{NG}$ & 203.2 & 155.3 & 111 \\
\hline 7 & 1 & 469.23 & 444.51 & 421.97 & 344.15 & 346.08 & 344.41 & 349.04 & 343.71 & 348.4 & 332.28 & 338.69 & 339.26 & 334.35 & 340.86 & $N G$ & 272.95 & 201.48 & 135.9 \\
\hline 8 & 1 & 683 & 643 & 605.1 & 506.23 & 508.77 & 506.73 & 512.09 & 505 & 511.84 & 493.13 & 495.7 & 496.4 & 490.34 & 499.46 & NG & 393.99 & 279.13 & 169.1 \\
\hline 9 & 1 & 198.7 & 192 & 186 & 163.5 & 163.87 & 163.25 & 165.3 & 163.2 & 165.37 & 156.18 & 158.76 & 159.26 & 156.88 & 158.98 & $\mathrm{NG}$ & 133.5 & 113.5 & 94.2 \\
\hline 10 & 1 & 190.7 & 183.9 & 178.1 & 157.38 & 157.68 & 157.11 & 158.86 & 157.22 & 158.89 & 150.62 & 152.1 & 153.04 & 150.78 & 152.44 & $\mathrm{NG}$ & 129.8 & 111 & 93.2 \\
\hline 11 & 1 & 345.56 & 330.62 & 315.8 & 264.74 & 266.26 & 264.07 & 268.37 & 264.82 & 268.37 & 255.59 & 258.6 & 264.42 & 255.5 & 259.2 & $\mathrm{NG}$ & 210.5 & 166.3 & 123.8 \\
\hline 12 & 1 & 365.62 & 350.64 & 335.35 & 279.69 & 282.16 & 279.44 & 284.2 & 279.7 & 284 & 270.28 & 273.74 & 274.87 & 270.02 & 274.75 & $N G$ & 221.2 & 172.6 & 127.3 \\
\hline 13 & 1 & 491.29 & 467.26 & 445 & 366.82 & 368.68 & 366.73 & 371.39 & 366.5 & 371.68 & 356.84 & 358.51 & 354.99 & 355 & 361.2 & NG & 282.62 & 212.42 & 147.2 \\
\hline 14 & 1 & 479.8 & 456.6 & 434.77 & 352.65 & 354.05 & 352.06 & 356.31 & 351.57 & 356.6 & 342.52 & 344.10 & 341.72 & 340 & 346.14 & $\mathrm{NG}$ & 271.5 & 204.38 & 142.2 \\
\hline 15 & 1 & 653.1 & 623 & 582.56 & 490.14 & 491.94 & 490.58 & 495.28 & 489.32 & 495.74 & 479.54 & 478.85 & 476.97 & 475.45 & 483.09 & $\mathbb{N G}$ & 375.8 & 274.04 & 178 \\
\hline 16 & 1 & 670.5 & 633.1 & 599.04 & 513.44 & 515.06 & 514.42 & 518.6 & 513.14 & 519.74 & 503.64 & 501.54 & 500.61 & 497.31 & 505.76 & NG & 393.75 & 286.25 & 184.55 \\
\hline 17 & 1 & 170 & 164.7 & 159.2 & 148.7 & 148.38 & 148.21 & 149.02 & 148.62 & 148.62 & 148.48 & 148.48 & 146.76 & 148.70 & 148.7 & NG & 130.1 & 110.8 & 92.5 \\
\hline 18 & 1 & 301.98 & $\mathrm{NG}$ & 275.78 & 248.65 & 248.55 & 247.85 & 250.05 & 248.9 & 249.67 & 248.69 & 248.52 & 247.6 & 248.4 & 248.3 & NG & 205.58 & 159.9 & 116.6 \\
\hline 19 & 1 & 440.71 & 417.71 & 396.33 & 352.82 & 352.85 & 351.96 & 353.08 & 352.98 & 353.94 & 352.61 & 352.65 & 351.59 & 351.83 & 352.53 & $\mathrm{NG}$ & 284.95 & 210.37 & 148.7 \\
\hline 20 & 1 & 662.8 & 625 & 590 & 517.6 & 517.63 & 518.4 & 518.38 & 516.64 & 518.35 & 515.26 & 515.75 & 514.12 & 512.09 & 515.06 & $N G$ & 411.82 & 293.8 & 182.3 \\
\hline 21 & 2 & 219.52 & 213.71 & 208.16 & 172.74 & 172.66 & 171.15 & 171.74 & 170.9 & 171.12 & NG & 165.2 & 160.1 & 166.77 & 167.37 & 166.45 & 138.2 & 117.7 & 103.6 \\
\hline 22 & 2 & 587.85 & 567.37 & 546.7 & 441.5 & 441.7 & 438.7 & 438.6 & 437 & 439 & NG & 422.5 & 404.3 & 426.1 & 426.4 & 424.8 & 325.97 & 255.65 & 205.45 \\
\hline 23 & 2 & 753.2 & 718.4 & 687.75 & 552.6 & 552.6 & 549.5 & 550.2 & 548.8 & 550.7 & NG & 528.1 & 506.2 & 533.9 & 535.2 & 532.7 & 400.74 & 310.43 & 244.4 \\
\hline 24 & 2 & 730.3 & 695.4 & 664.7 & 526 & 526 & 522.2 & 522.2 & 520.5 & 520.2 & NG & 501.2 & 473 & 504 & 504.5 & 501.2 & 364.5 & 269.3 & 200.5 \\
\hline 25 & 3 & 172.2 & 167.1 & 162.2 & 148,8 & 148.7 & 148.2 & 150.8 & 150.6 & 150 & 147.6 & 147.6 & 147.4 & 146.1 & 146 & 146.3 & 128.4 & 110.9 & 94.2 \\
\hline 26 & 3 & 305 & 293 & 280.8 & 249.02 & 249.64 & 248.31 & 253 & 252.84 & 251.8 & 246.21 & 246.88 & 246.88 & 243 & 243.1 & 243.65 & 201.8 & 157.8 & 116.9 \\
\hline 27 & 3 & 421.98 & 402.2 & 383.6 & 338.46 & 340.03 & 338.56 & 344.28 & 344.04 & 342.87 & 335.21 & 336.42 & 336.3 & 331.4 & 331.2 & 331.97 & 266.72 & 200.16 & 139.3 \\
\hline 28 & 3 & 632.5 & 597,33 & 566,4 & 500.96 & 503.59 & 501.8 & 508.32 & 507.72 & 506.16 & 496.02 & 499.02 & 494.46 & 490.02 & 490.86 & 492.06 & 384.78 & 278 & 177.2 \\
\hline 29 & 3 & 161.8 & 157.5 & 152.6 & 141.52 & 141.26 & 140.26 & 141.88 & 141.88 & 141.46 & 141.32 & 141.32 & 141.09 & 141.09 & 141.18 & 141.09 & 124.7 & 107.8 & 90.9 \\
\hline 30 & 3 & 303.5 & 290.58 & 277.67 & 251.88 & 251.55 & 249.92 & 252.45 & 252.15 & 251.75 & 250.92 & 250.7 & 250.92 & 250.67 & 250.95 & 250.95 & 205.8 & 160.8 & 118.5 \\
\hline 31 & 3 & 432.55 & 413.07 & 392.94 & 351.35 & 351.58 & 349.98 & 352.6 & 352.28 & 351.15 & 350.5 & 350.87 & 350.47 & 349.72 & 350.45 & 350.72 & 281.85 & 209.66 & 143 \\
\hline 32 & 3 & 630.7 & 595.39 & 563.29 & 500.96 & 502.4 & 501.2 & 503.36 & 502.88 & 501.2 & 499.52 & 500.72 & 497.84 & 498.8 & 499.76 & 500.24 & 397.3 & 286.64 & 182.36 \\
\hline
\end{tabular}


TABLE 1 (continued)

\begin{tabular}{|c|c|c|c|c|c|c|c|c|c|c|c|c|c|c|c|c|c|c|c|}
\hline \multirow{2}{*}{$\begin{array}{l}\text { Test } \\
\text { No. }\end{array}$} & \multirow{2}{*}{$\begin{array}{l}\text { Spec } \\
\text { No. }\end{array}$} & \multicolumn{3}{|c|}{ Input Heat Meter } & \multicolumn{6}{|c|}{ Hot Half of Specimen } & \multicolumn{6}{|c|}{ Cold Half of Specimen } & \multicolumn{3}{|c|}{ Output Heat Meter } \\
\hline & & 1 & 2 & 3 & $* 4$ & 5 & 6 & 7 & 8 & 9 & $* 10$ & 11 & 12 & 13 & 14 & 15 & 16 & 17 & 18 \\
\hline 33 & 4 & 210.8 & 207.71 & 204.7 & 161.8 & 163 & 163.4 & 164.6 & & & 151 & 149.5 & 150.1 & 149.2 & & & 106 & 96.2 & 85.6 \\
\hline 34 & 4 & 351.77 & 34.4 .34 & 337.95 & 254.3 & 256.5 & 257 & 259.1 & & & 233.8 & 229.5 & 231.7 & 229.4 & & & 142.1 & 120.2 & 98.7 \\
\hline 35 & 4 & 513.68 & 500.75 & 489.54 & 371.5 & 375.1 & 376.7 & 379.5 & & & 345.5 & $338 . ?$ & 340.8 & 338 & & & 201.5 & 161 & 119.1 \\
\hline 36 & 4 & 702.5 & 679.8 & 660.7 & 606 & 611.7 & 615.2 & 619 & & & 569.2 & 561.7 & 562.4 & 558.3 & & & 274.8 & 213 & 146.8 \\
\hline 37 & 4 & 196.7 & 193.6 & 190.5 & 146.9 & 14.7 .1 & 147.1 & 147.8 & & & 146.3 & 146.6 & 146.5 & 146.1 & & & 104.2 & 94.9 & 84.8 \\
\hline 38 & 4 & 351.94 & 344.5 & 337.08 & 249 & 249.1 & 249,3 & 250 & & & 247.6 & 247.9 & 247.9 & 24.7 .1 & & & 152 & 127.5 & 102.8 \\
\hline 39 & 4 & 498,76 & 485.06 & 472.99 & 346.4 & 346.6 & 347.3 & 347,8 & & & 344 & 344.7 & 344.5 & 343.5 & & & 203.4 & 163.3 & 122 \\
\hline 40 & 4 & 700 & 676.9 & 657.3 & 592.1 & 592.43 & 594.05 & 594.59 & & & 588.18 & 589.72 & 588.88 & 586.92 & & & 292.8 & 226.4 & 156.4 \\
\hline 41 & 5 & 200.16 & 197.06 & 194.31 & 154.25 & 156.15 & 156.35 & 161.18 & 156.20 & 160.6 & 148 & 147.9 & 148.7 & 143.9 & 147.9 & 145.5 & 103 & 93.8 & 84.7 \\
\hline 42 & 5 & 333.07 & 326,17 & 319.67 & 238.38 & 242.74 & 242.93 & 252.11 & 243.19 & 251.11 & 225.93 & 225.48 & 226.84 & 216.77 & 225.03 & 216.81 & 134 & 113.8 & 93.8 \\
\hline 43 & 5 & 462.38 & 452.1 & 440.92 & 325.17 & 332.17 & 331.61 & 343.54 & 334.18 & 343.19 & 307.4 & 307.04 & 308.58 & 294.68 & 306.23 & 294.76 & 172.9 & 141.3 & 110 \\
\hline 44 & 5 & 691 & 672.8 & 652.5 & 490,44 & 502.17 & 499.6 & 512.91 & 506.91 & 514.88 & 462.1 & 463.52 & 465.24 & 446.9 & 460.66 & 445.43 & 261.28 & 201.3 & 140 \\
\hline 45 & 1 & 177.5 & 171.6 & 166.1 & 154.4 & 154.7 & 153.5 & 155.1 & 153.4 & 155.2 & 152.3 & 151.1 & 152.4 & 150.2 & 152 & NG & 130.2 & 110 & 90.3 \\
\hline 46 & 1 & 319.15 & 305.45 & 291.24 & 261.15 & 262.92 & 260.82 & 265.1 & 261.15 & 264.95 & 257.72 & 256.16 & 258.72 & 254.14 & 257.9 & $\mathrm{NG}$ & 208.63 & 161.5 & 118 \\
\hline 47 & 1 & 434.9 & 415.72 & 394.05 & 351.16 & 352.65 & 350.12 & 355.83 & 350.2 & 355.54 & 346.31 & 344.18 & 348.3 & 340.57 & 346.5 & NG & 259.18 & 203.87 & 137.5 \\
\hline 48 & 1 & 670.1 & 632.1 & 594,45 & 525.23 & 527.15 & 524.44 & 530.69 & 522.44 & 525.79 & 517.83 & 514.35 & 520.14 & 506.75 & 517.86 & NG & 404.71 & 289.29 & 178.8 \\
\hline 49 & 4 & 196.93 & 194.32 & 191.41 & 154.32 & 153.88 & 154.24 & 153.91 & & & 141.19 & 140.64 & 141.14 & 140.83 & & & 97.2 & 88 & 78.4 \\
\hline 50 & 4 & 343.03 & 337.75 & 330.92 & 256.06 & 254.87 & 256.16 & 255.26 & & & 228.3 & 227.3 & 228.51 & 230.78 & & & 135.5 & 114.2 & 93.1 \\
\hline 51 & 4 & 482.6 & 474.75 & 463.61 & 359.31 & 357.83 & 360.09 & 358.74 & & & 320.7 & 318.6 & 320.33 & 322.7 & & & 182.8 & 147.8 & 111 \\
\hline 52 & 4 & 678.2 & 659 & 640.6 & 501.34 & 499.9 & 503.26 & 501.34 & & & 452.02 & 448.9 & 451.06 & 454.18 & & & 257.26 & 199.95 & 139.3 \\
\hline
\end{tabular}


fastened together, taking care that the mating surfaces did not twist or rub against each other during the process. A torque wrench calibrated for each specific experimental value was used on the nut to assure that the prescribed bolt tension limits were maintained. In the case of the riveted joint, standard riveting tools and processes were used for installing and heading the rivet. This was done in an effort to produce the conditions that would exist in the joint as the result of a typical assembly of this kind. After the input and output heat meters were in place, the heat sink was insulated with 10 layers of mylar-coated aluminum foil. A radiation shield consisting of four layers of highly polished and dimpled stainless steel sheet was placed over the entire test fixture. When power leads, water lines and thermocouples were hooked up and checked out, the chamber was closed and pump down started. Specimen 1, installed in the test fixture prior to being insulated, can be seen in Fig. 3. Figure 5 shows the same specimen completely installed in the chamber with the radiation shield in place.

By regulating the flow of water through the heat sink and the amount of power applied to the heater, various joint temperature levels were attained. Temperature data were taken every 10 minutes until stable thermal conditions were reached. The definition of stable thermal conditions established for purposes of this test was that point when the change in temperature indicated by Thermocouple 4 (located on the hot mating surface) did not vary more than $0.5^{\circ} \mathrm{K}$ in 15 minutes. When this condition was reached, all thermocouple outputs, heater power input and chamber pressure were recorded. A tabulated listing of the data obtained for each test run can be obtained from Table 2. Both Table 1 and Table 2 must be used together.

5. Data Presentation

a. Data reduction procedure

The data obtained from the joint conductance thermal tests consisted of quasi-steady state temperatures at the following points:

(1) Three locations spaced one inch apart in the direction of heat flow through the Armco iron heat meter $(2.54 \mathrm{~cm}$ diameter) upstream of the contact point

(2) Six (or four) different locations close to the interface on the hotter side of the contact plane

(3) Six (or four) different locations close to the interface on the colder side of the contact plane

(4) Three locations spaced one inch apart in the direction of heat flow through the Armco iron heat meter (1.27 cm diameter) downstream of the contact point. 


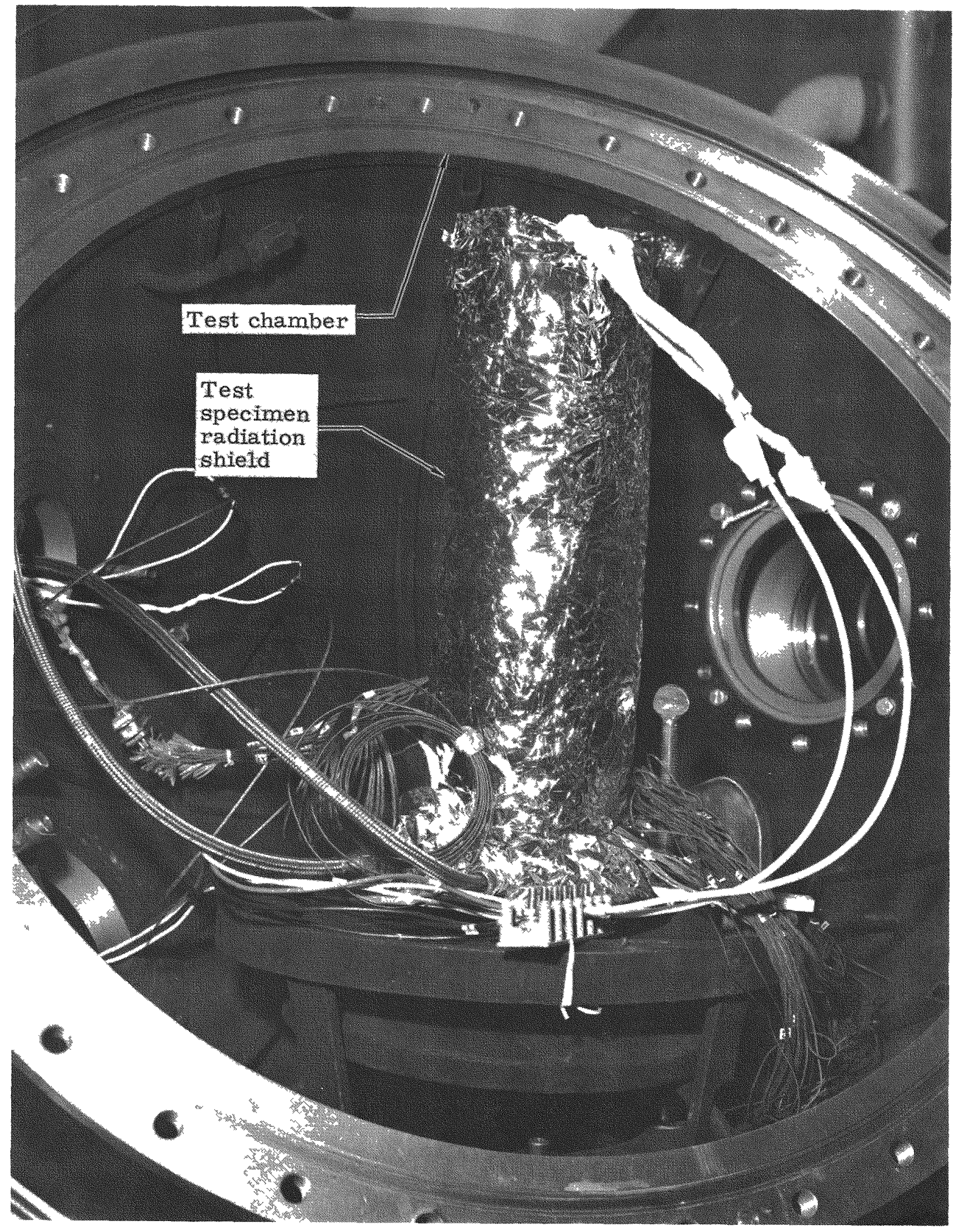

Fig. 5. Test Specimen Installed in Test Chamber 
TABLE 2

Test Conditions and Results

\begin{tabular}{|c|c|c|c|c|c|c|c|c|c|c|c|}
\hline \multirow[b]{2}{*}{$\begin{array}{l}\text { Test } \\
\text { No. } \\
\end{array}$} & \multirow[b]{2}{*}{$\begin{array}{l}\text { Specimen } \\
\text { No }\end{array}$} & \multirow[b]{2}{*}{ Material } & \multirow[b]{2}{*}{ Fastening } & \multirow[b]{2}{*}{$\begin{array}{l}\text { Torque } \\
\text { (1n-1b) } \\
\end{array}$} & \multirow[b]{2}{*}{ Greased } & \multirow{2}{*}{$\begin{array}{c}\text { Chamber } \\
\text { Pressure } \\
\text { (torr) } \\
\end{array}$} & \multirow{2}{*}{$\begin{array}{c}\text { Jount } \\
\text { Temperature } \\
\text { ("F) } \\
\end{array}$} & \multirow[b]{2}{*}{ Scale } & \multirow{2}{*}{$\begin{array}{c}\text { Average } \\
\text { Feat } \\
\text { Rate } \\
\text { (Btu/hr) } \\
\end{array}$} & \multicolumn{2}{|c|}{ Joint Conductance } \\
\hline & & & & & & & & & & $\left(B t u / h r-f^{2}-{ }^{\circ} \mathrm{F}\right)$ & $\left(\right.$ watt $\left./ \mathrm{m}^{2}-^{\circ} \mathrm{K}\right)$ \\
\hline 1 & 1 & ZH62A-A1 & Elex bolt & 55 & No & $1 \times 10^{-2}$ & 532 & Full & 7345 & 350 & 1,985 \\
\hline 2 & 4 & 1 & 1 & 1 & 1 & $1 \times 10^{-2}$ & 340 & 1 & 4755 & 388 & 2,200 \\
\hline 3 & & & & & & $1 \times 10^{-2}$ & 245 & & 3180 & 522 & 2,960 \\
\hline 4 & & & & & & $1 \times 10^{-2}$ & 148 & & 1259 & 361 & 2,046 \\
\hline 5 & & & & & & $3 \times 10^{-5}$ & 145 & & 1316 & 245 & 1,390 \\
\hline 6 & & & & & & $3 \times 10^{-5}$ & 248 & & 3270 & 345 & 1,957 \\
\hline 7 & & & & 1 & & $2 \times 10^{5}$ & 344 & & $46 \quad 65$ & 304 & 1,724 \\
\hline 8 & & & & 55 & & $2 \times 10^{-5}$ & 506 & & 7105 & 304 & 1,724 \\
\hline 9 & & & & 40 & & I $75 \times 10^{-5}$ & 164 & & 1452 & 136 & 772 \\
\hline 10 & & & & 1 & & $1 \times 10^{-2}$ & 157 & & 1409 & 131 & 744 \\
\hline 11 & & & & & & $1 \times 10^{-2}$ & 265 & & 3130 & 193 & 1,095 \\
\hline 12 & & & & & & $1.75 \times 10^{-5}$ & 280 & & 3265 & 214 & 1,214 \\
\hline 13 & & & & & & $1 \times 10^{-5}$ & 367 & & 4592 & 243 & 1,380 \\
\hline 14 & & & & & & $1 \times 10^{-2}$ & 353 & & 4570 & 246 & 1,396 \\
\hline 15 & & & & 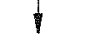 & 1 & $1 \times 10^{-2}$ & 490 & & 6400 & 275 & 1,560 \\
\hline 16 & & & & 40 & No & $1.5 \times 10^{-5}$ & 513 & & 6550 & 271 & 1,539 \\
\hline 17 & & & & 55 & Yes & $4 \times 10^{-4}$ & 149 & & 1310 & 1930 & 10,950 \\
\hline 18 & & & & 1 & 1 & $16 \times 10^{-4}$ & 249 & & $30 \quad 08$ & 3280 & 18,600 \\
\hline 19 & 1 & & 1 & 1 & 1 & $35 \times 10^{-5}$ & 353 & & $46 \quad 65$ & 5090 & 28,850 \\
\hline 20 & 1 & & Hex bolt & 55 & Yes & $32 \times 10^{-5}$ & 518 & & 6940 & 1155 & 6,570 \\
\hline 21 & 2 & & Rivet & -- & No & $1 \times 10^{-2}$ & 173 & & 1358 & 143 & 813 \\
\hline 22 & 1 & & 1 & $\$$ & 1 & $1 \times 10^{-2}$ & 442 & & 4185 & 161 & 915 \\
\hline 23 & 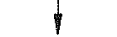 & & 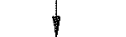 & 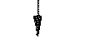 & & $1 \times 10^{-2}$ & 553 & & 5400 & 163 & 926 \\
\hline 24 & 2 & & Rivet & - & & $1 \times 10^{-5}$ & 526 & & $56 \quad 60$ & 158 & 898 \\
\hline 25 & 3 & & Counter- & 55 & & $32 \times 10^{-5}$ & 149 & & 1201 & 244 & 1,385 \\
\hline 26 & 1 & & sunk bolt & 1 & & $2.6 \times 10^{-5}$ & 249 & & $28 \quad 10$ & 263 & 1,492 \\
\hline 27 & & & & & & $2.7 \times 10^{-5}$ & 338 & & 4150 & 297 & 1,685 \\
\hline 28 & & & & & No & $25 \times 10^{-5}$ & 501 & & 6190 & 306 & 1,735 \\
\hline 29 & & & & & Yes & $9 \times 10^{-5}$ & 142 & & 1149 & 1560 & 8,870 \\
\hline 30 & & & & & 1 & $5.5 \times 10^{-5}$ & 252 & & 2940 & 1430 & 8,130 \\
\hline 31 & 1 & 1 & Counter- & 1 & 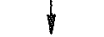 & $4 \times 10^{-5}$ & 351 & 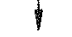 & 4370 & 1775 & 10,070 \\
\hline 32 & 3 & $\mathrm{ZH} 62 \mathrm{~A}-\mathrm{Al}$ & sunk bolt & 55 & Yes & $32 \times 10^{-5}$ & 501 & Fuil & 65.30 & 1410 & 8,020 \\
\hline 33 & 4 & 304 CRES & Hex bolt & 975 & No & $3.2 \times 10^{-5}$ & 162 & $1 / 2$ & 720 & 926 & 525 \\
\hline 34 & 1 & 1 & 1 & 1 & 4 & $32 \times 10^{-5}$ & 254 & 1 & 1443 & 955 & 542 \\
\hline 35 & & & & & & $3 \times 10^{-4}$ & 372 & & 2592 & 125 & 711 \\
\hline 36 & & & & & No & $4 \times 10^{-4}$ & 606 & & 3942 & 134 & 762 \\
\hline 37 & & & & & Yes & $13 \times 10^{-4}$ & 147 & & 714 & 1425 & 8,100 \\
\hline 38 & & & & & & $8 \times 10^{-5}$ & 249 & & 1666 & 1635 & 9,260 \\
\hline 39 & 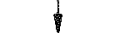 & & & 1 & 1 & $8 \times 10^{-5}$ & 346 & 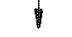 & 2675 & 1590 & 9,040 \\
\hline 40 & 4 & 304 CRES & & 975 & Yes & $7 \times 10^{5}$ & 592 & $1 / 2$ & 4100 & 1425 & 8,100 \\
\hline 41 & 5 & 347 CRES & & 55 & No & $2.8 \times 10^{-4}$ & 154 & Full. & 672 & 35 & 199 \\
\hline 42 & 1 & & & 4 & 1 & $47 \times 10^{-5}$ & 238 & 1 & 1444 & 354 & 201 \\
\hline 43 & 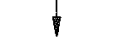 & $\gamma$ & & & & $4 \times 10^{-5}$ & 325 & & 2180 & 373 & 212 \\
\hline 44 & 5 & 347 CRES & & & & $25 \times 10^{-5}$ & 490 & & 3695 & 428 & 243 \\
\hline 45 & 1 & ZH62A-A1 & & & & $3 \times 10^{-4}$ & 154 & & 1388 & 289 & 1,640 \\
\hline 46 & 1 & 1 & & & & $14 \times 10^{-4}$ & 261 & & 3103 & 320 & 1,815 \\
\hline 47 & 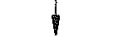 & 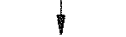 & & 1 & & $22 \times 10^{-5}$ & 351 & 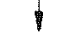 & 4185 & 335 & 1,900 \\
\hline 48 & 1 & $\mathrm{ZH} 62 \mathrm{~A}-\mathrm{Al}$ & & 55 & & $2.2 \times 10^{-5}$ & 525 & Full & 7000 & 360 & 2,044 \\
\hline 49 & 4 & 304 CRES & & 9.75 & & $55 \times 10^{-5}$ & 154 & $1 / 2$ & 675 & 871 & 494 \\
\hline 50 & 1 & 1 & & 1 & & $43 \times 10^{-5}$ & 256 & 1 & 1492 & 948 & 538 \\
\hline 51 & 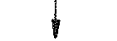 & 1 & 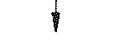 & 1 & $\varphi$ & $2.5 \times 10^{-5}$ & 359 & 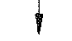 & $23 \quad 15$ & 102 & 580 \\
\hline 52 & 4 & 304 CRES & Hex bolt & 9.75 & No & $23 \times 10^{-5}$ & 501 & $1 / 2$ & 3525 & 120 & 682 \\
\hline
\end{tabular}


In addition to these temperature measurements, test data included the chamber pressure and the heater voltage and current.

When reducing the data, the heat flow rate, $q$, is calculated as

$$
q=(k A \Delta T) / x
$$

where $\mathrm{x}$ is the meter length corresponding to the temperature rise or drop, $\Delta \mathrm{T}$.

From the six heat meter temperatures, four different values of the heat flow rate for each test were calculated. Due to progressive heat loss by radiation and residual gas conduction, the calculated heat flow rate normally showed a reduction from one heat meter section to the next. This occurred even though there was a radiation shield. How ever, since the contact joint is approximately centered between the various heat meter sections, it can be reasonably assumed that the heat flow rate through the joint is the arithmetical average of the four different rates calculated.

The thermal conductance of the joint is calculated as

$$
h=q_{a v e} / A_{i j} \Delta T_{i j}
$$

where $A$ is the surface area of the contact and $T$ is the temperature drop across the joint.

The mean temperature difference across the contact interface, $T_{i j}$ is calculated by subtracting the average of six (or four) temperatures on the cold side of the interface from the average of six (or four) temperatures on the hot side of the interface.

b. Test results

The total number of tests conducted amounted to 52, using five different contact joints as described previously. Thermocouple readings from all tests are presented in Table 1. Test conditions and results of calculated thermal conductance for each condition are presented in Table 2. Figure 6 shows the thermal conductance of specimens with clean surfaces of contact, and Fig. 7 illustrates those with contacting surfaces coated with a special thermal grease impregnated with silver powder per General Electric Specification 171A4157. 


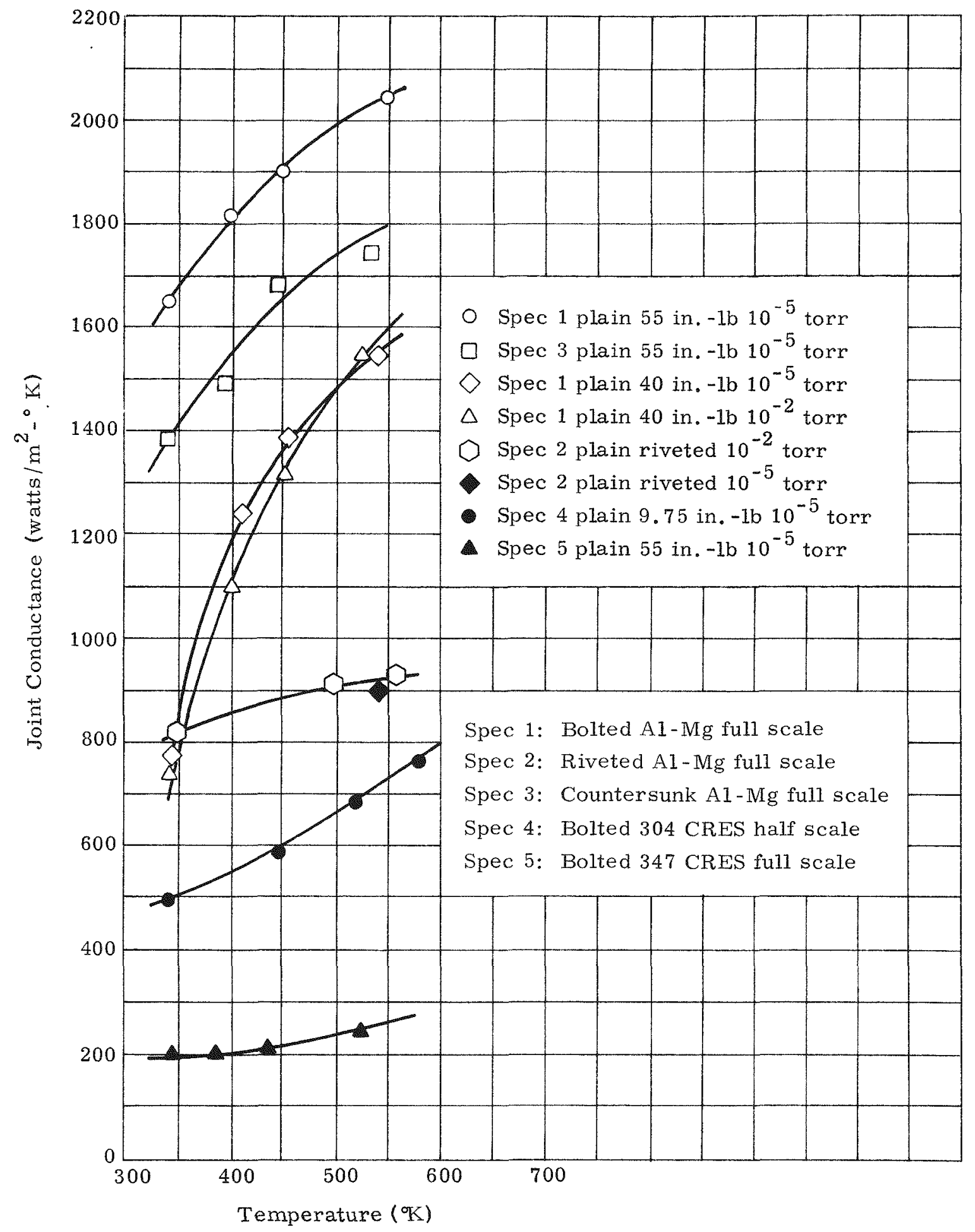

Fig. 6. Joint Thermal Conductance Versus Temperature for Ungreased Joints 


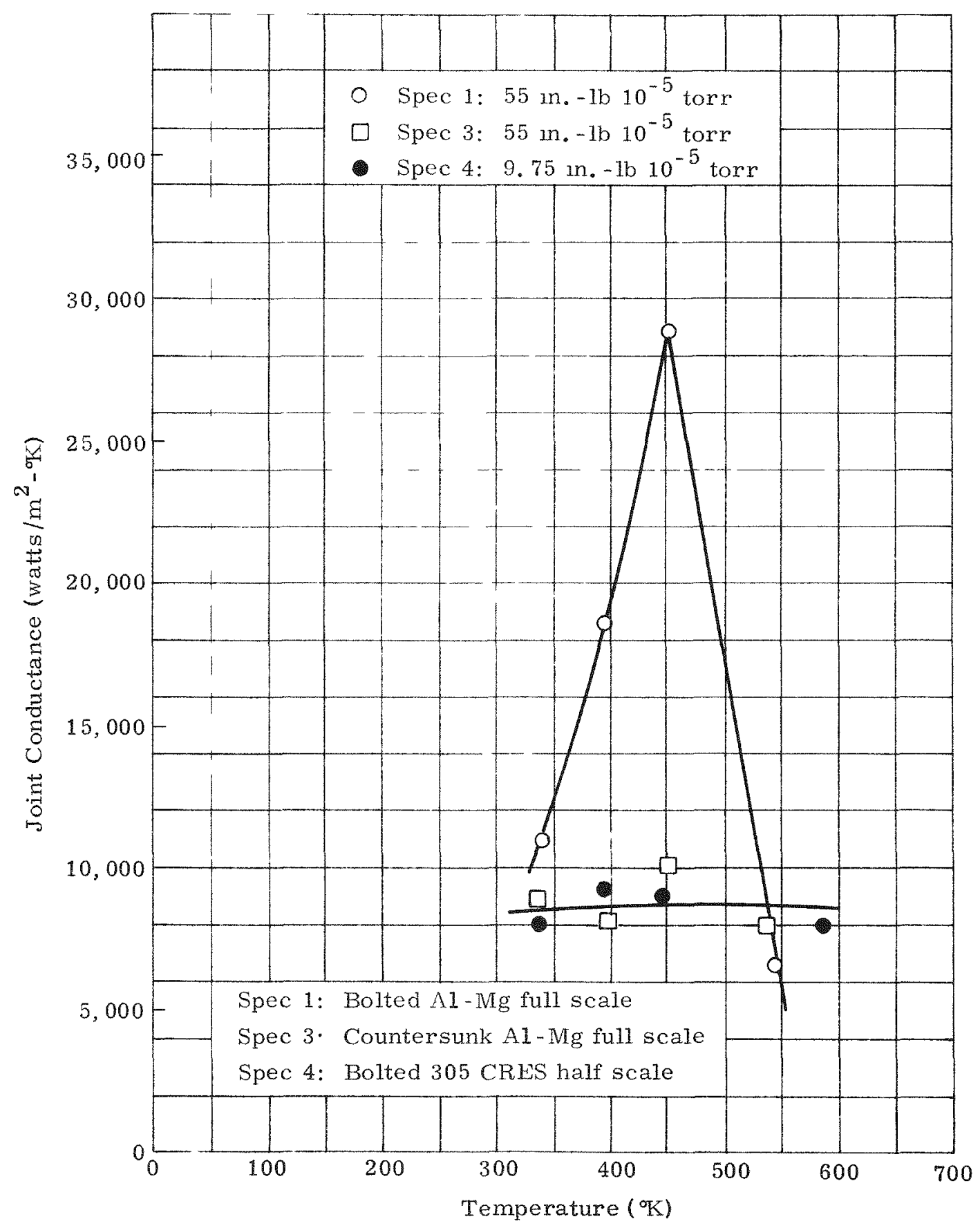

Fig. 7. Joint Thermal Conductence Versus Temperature for Greased Joints 


\section{B. THERMAL AND MECHANICAL PROPERTIES OF ZH62A ALLOY}

\section{Emissivity Measurement}

Both the total hemispherical and normal emittances were determined. Since emittance is also dependent upon the conditions of the surface, each specimen surface was finished to match that specified for the Nimbus B structure.

The total hemispherical emittance was determined using the calorimetric test method at the Martin Test Facility. A hollow cylindrical test specimen whose interior was heated electrically was suspended by the power leads in the center of the evacuated and cooled test chamber. Figure 8 illustrates the test specimen and Fig. 9 shows the facility. The chamber pressure was maintained below $10^{-5}$ torr to keep the heat loss by means of gaseous convection at a negligible level. After the specimen had reached thermal equilibrium, its emittance was calculated from the known relationship between the electrical power dissipated, area and equilibrium temperature of the specimen. Suitable corrections were made for electrical resistance and thermal conductivity losses in the heater leads. Test results at two temperature levels are as follows:

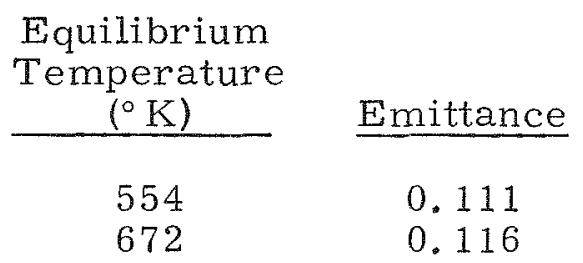

The total normal emittance was determined through the use of a GierDunkle reflectometer shown in Fig. 10, using a single beam monochromator. The test specimen was made of a flat disc of ZH62A alloy. The reflectance was measured in an integrating sphere for wave lengths from 0.295 to 2.7 microns in $2 \%$ increments of the Johnson curve. The sample was transferred to the heated cavity, and reflectance measurements were made at from 1.4 to 25 microns. The total normal emittance was then determined by integration of the reflectance curve for every $2 \%$ increment of the Planckian curve for distribution of energy of a black body at $610^{\circ}$ and $700^{\circ} \mathrm{K}$.

Next, the specimen was subjected to simulated use conditions for two hours. This consisted of placing it in a vacuum chamber at a 20to 30 -micron pressure level while holding the temperature of the specimen at $682^{\circ} \mathrm{K}$. After this, the total normal emittance was again determined in the same manner as before. The calculated results of the total normal reflectance tests were as follows: 


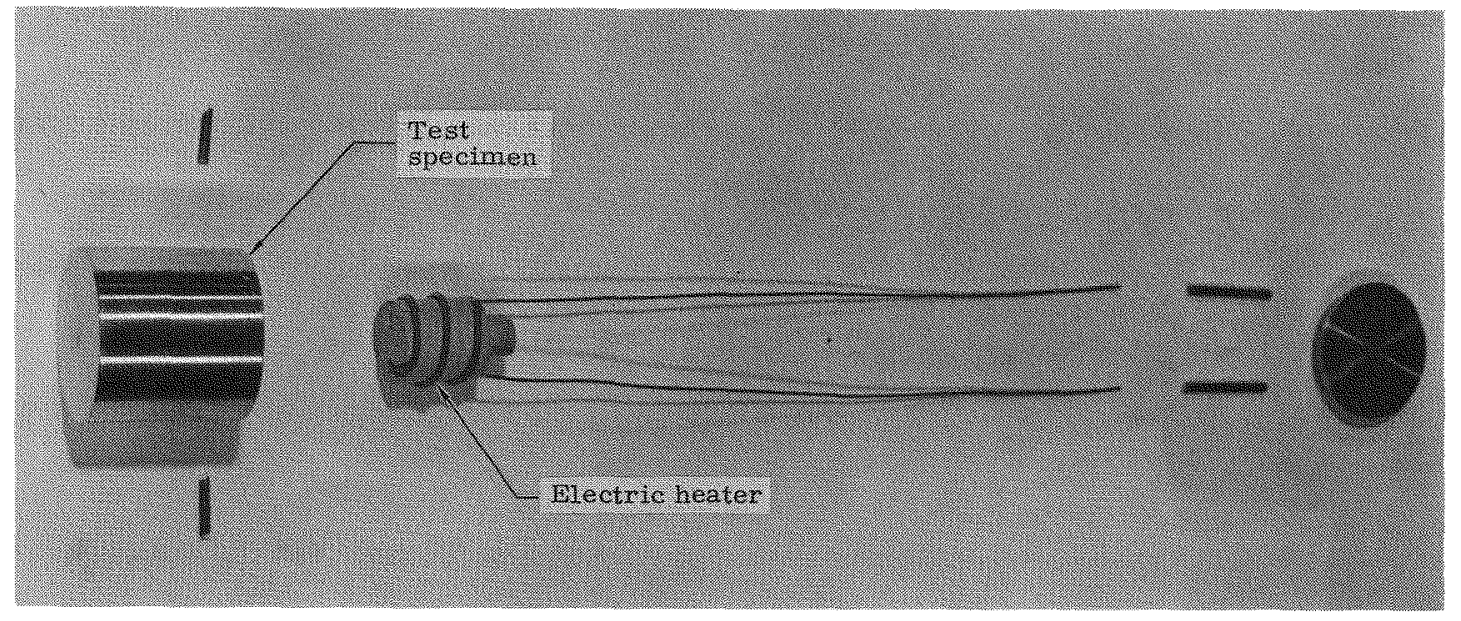

Fig. 8. Test Specimen Used in Total Hemispherical Emittance Test

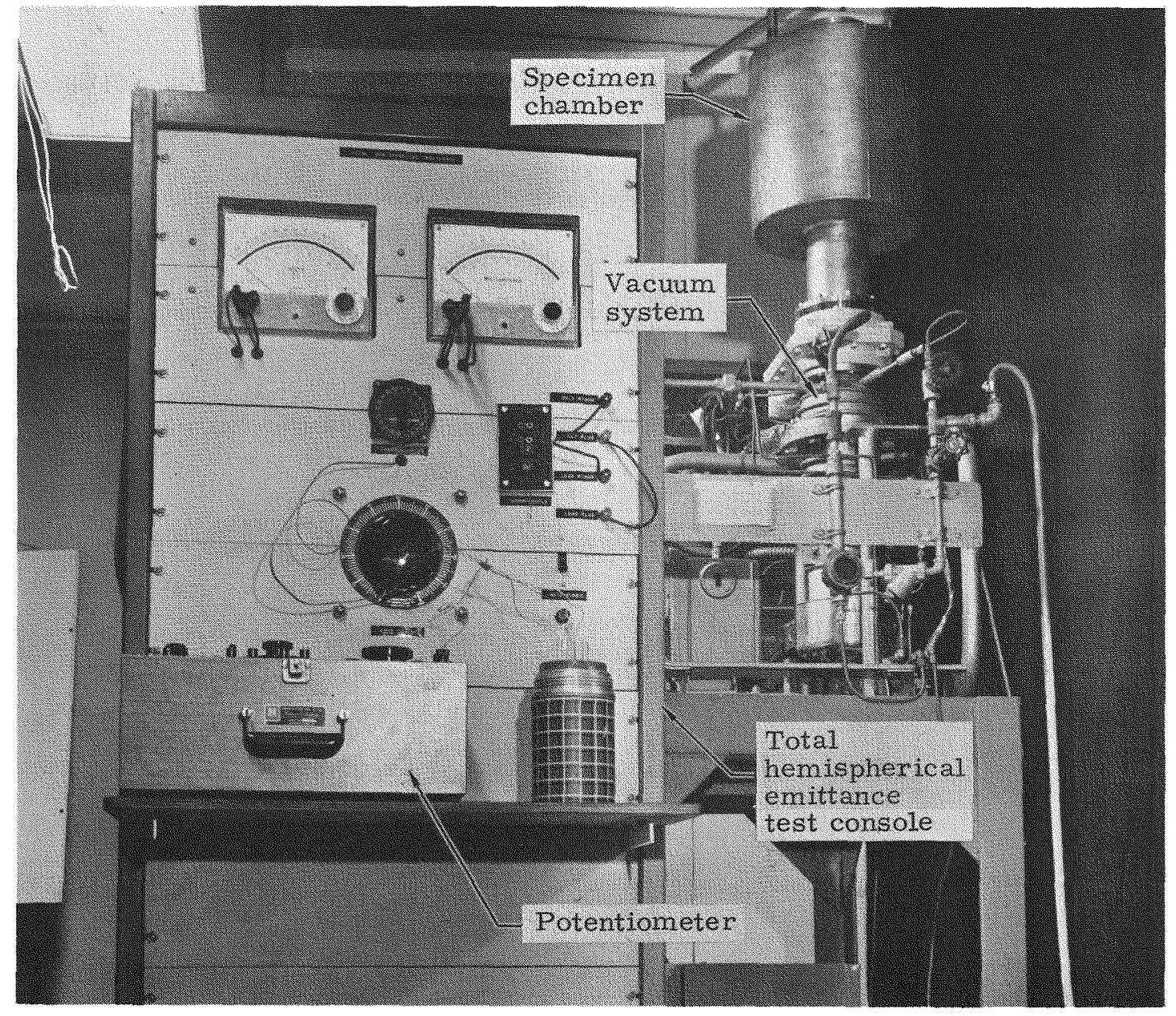

Fig. 9. Test Facility Used for Total Hemispherical Emittance Test 


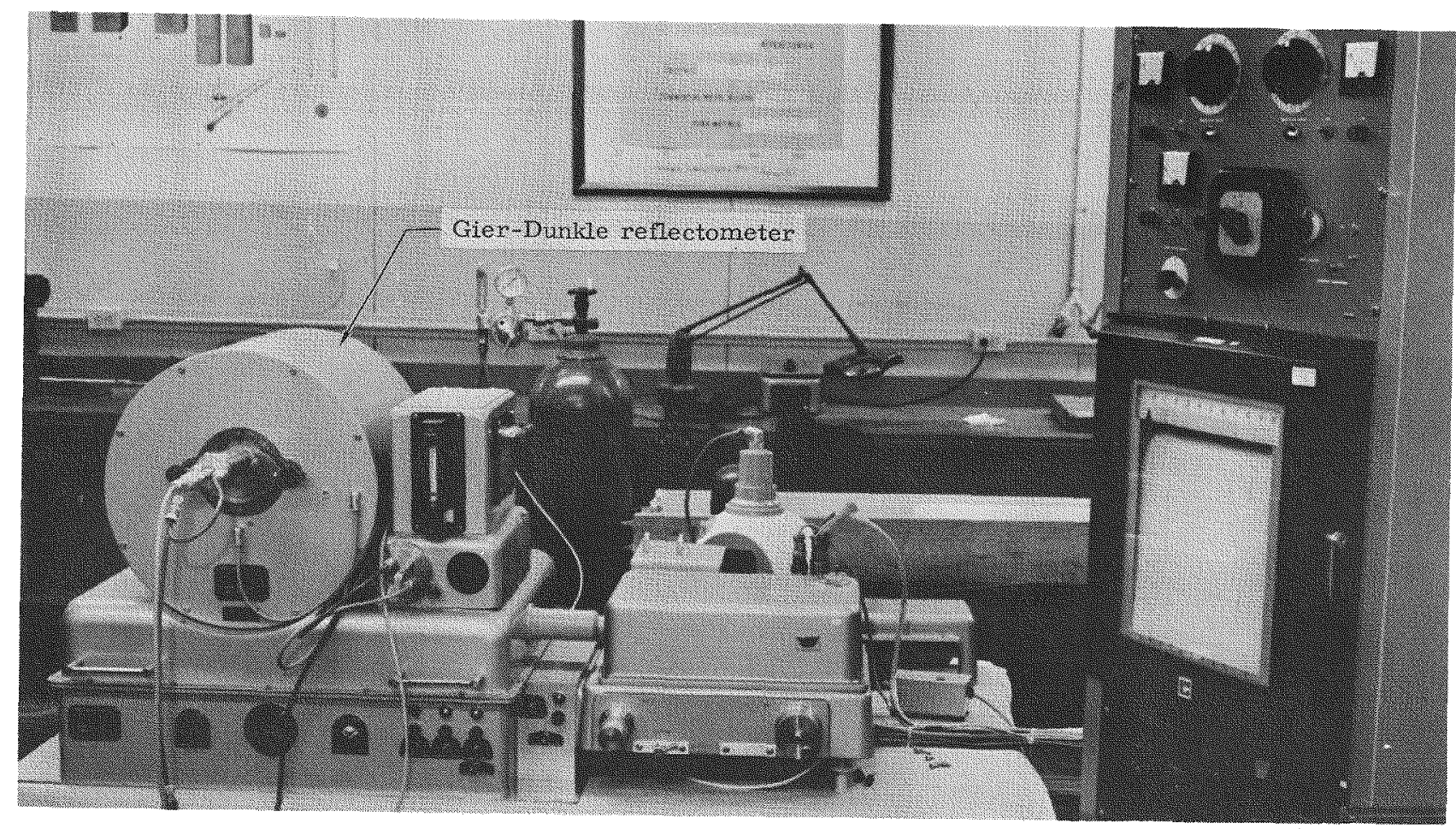

Fig. 10. Test Facility Used for Spectral Reflectance Test

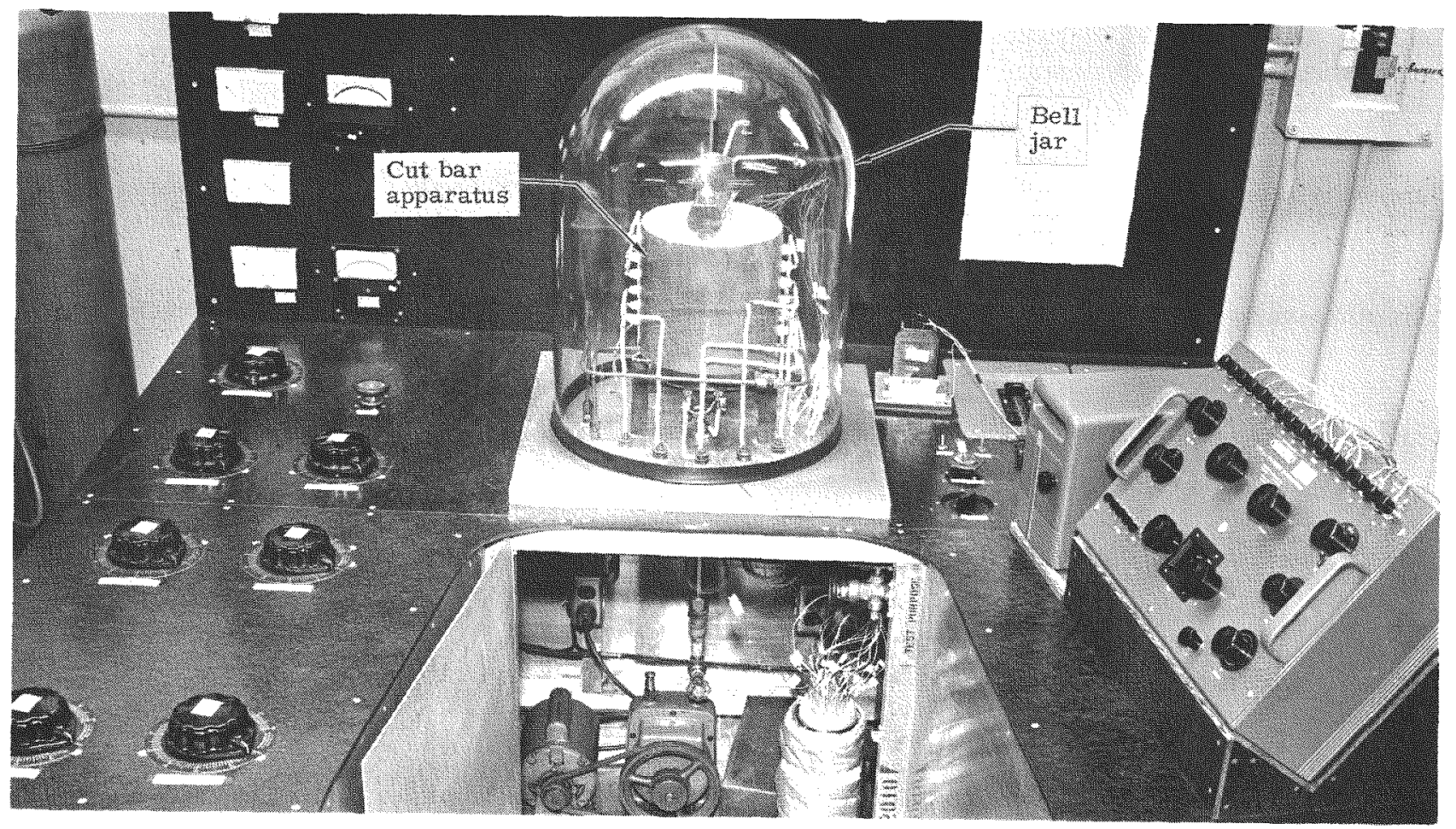

Fig. 11. Test Facility Used for Thermal Conductance Test 


\begin{tabular}{|c|c|c|}
\hline Temperature $\left({ }^{\circ} \mathrm{K}\right)$ & $\begin{array}{c}E \\
\text { Original }\end{array}$ & $\begin{array}{c}\mathrm{E} \\
\text { After Vacu } \\
\end{array}$ \\
\hline 610 & 0.080 & 0.081 \\
\hline 700 & 0.089 & 0.091 \\
\hline
\end{tabular}

\section{Thermal Conductivity Measurement}

Thermal conductivity measurements were made at temperatures ranging from $600^{\circ}$ to $783^{\circ} \mathrm{K}$ in an inert argon atmosphere using the Martin cut bar apparatus pictured in Fig. 11. This equipment compares the known thermal conductivity of a standard material with that of the specimen being tested. The test specimen and standard, including a system of thermal guard zones, are stacked together in a manner which ensures that parallel isotherms exist in the stacks. The standard acts as a metering bar for determining the heat flux to which the specimen is subjected. The precise measurements required to determine the temperature gradient through the standard and test specimen are made with platinum-rhodium thermocouples which are accurate to $0.1^{\circ} \mathrm{C}$. The conductivity of the specimen being tested is determined mathematically after the heat flow rate and temperature gradient through the material are known. The thermal conductivity of this material based on the results of this test is described by the curve in Fig. 12.

\section{Specific Heat Measurements}

An adiabatic drop calorimeter was used as the tool to determine the specific heat of the specimen material at temperatures ranging from $583^{\circ}$ to $783^{\circ} \mathrm{K}$. This apparatus consisted of a furnace, 3.8 centimeters in diameter and 51 centimeters long, connected to a calorimeter through a straight tube as pictured in Fig. 13. The furnace was purged with helium to minimize oxidation of the test specimen. The calorimeter containing a known mass of water is surrounded by a protective jacket which is maintained at the same temperature as the water. A special gate located at the top of the receiver prevents heat loss due to radiation during the dropping action.

For each temperature level of interest, the specimen is suspended in the furnace until steady state thermal conditions exist. The specimen is then dropped into the water of the calorimeter and left there until water and specimen reach the same temperature level. The specific heat is then calculated from the known values of specific heat, mass and temperature increase of the water, and the mass and temperature decrease of the specimen. The curve shown in Fig. 14 is the result of tests performed according to this procedure for the subject material. 


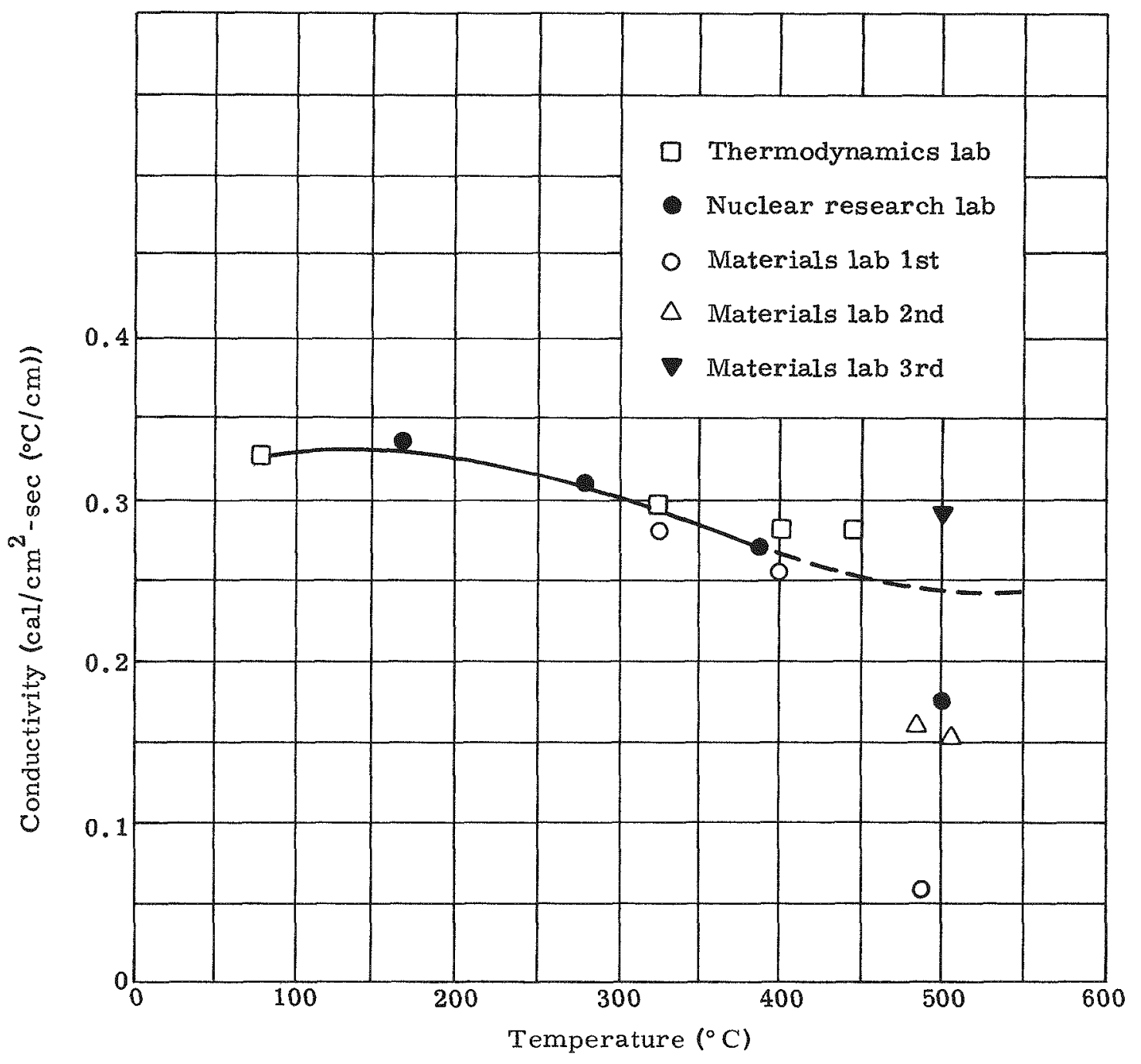

Fig. 12. Thermal Conductivity of ZH62A Versus Temperature 


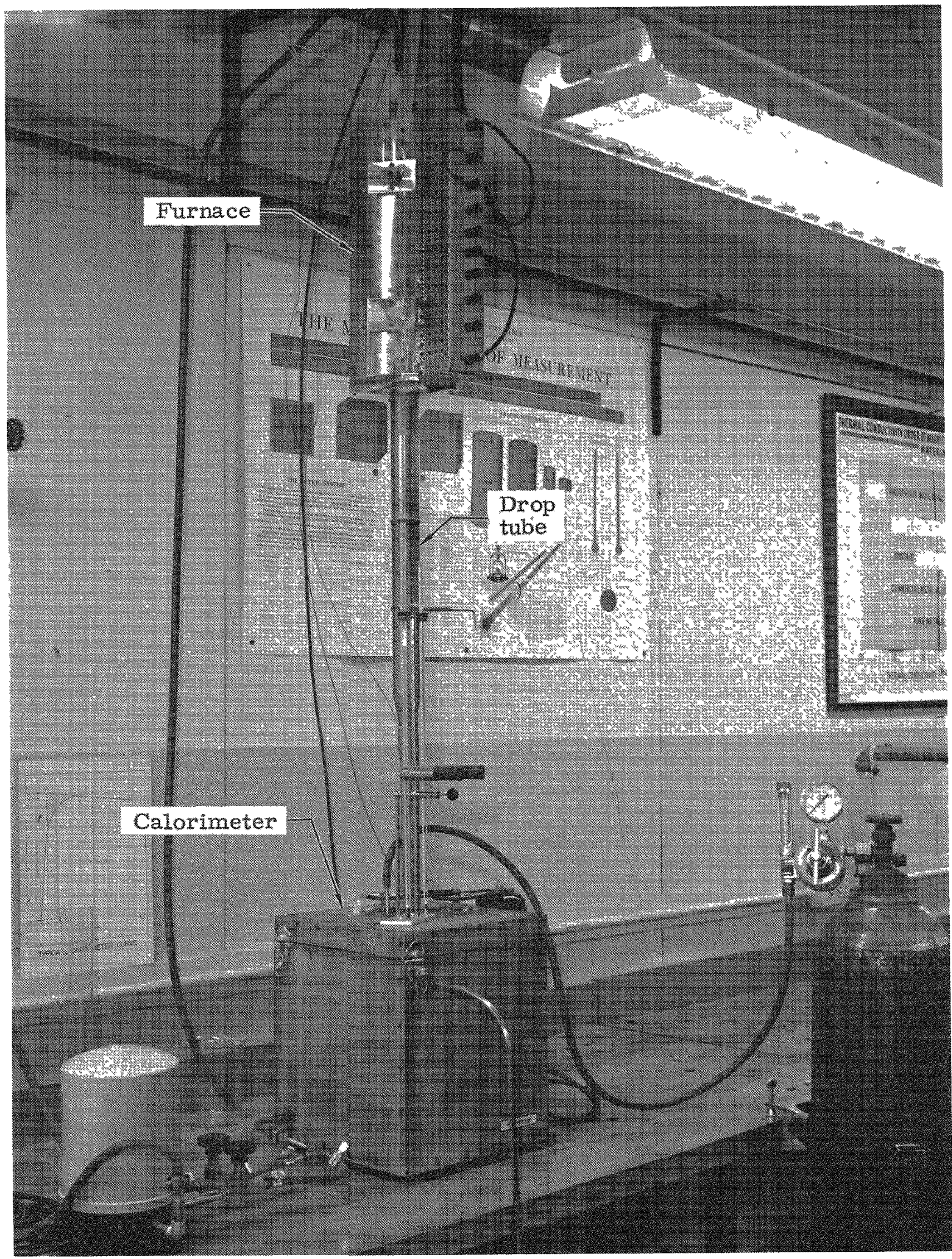

Fig. 13. Test Facility Used for Specific Heat Test--Drop Calorimeter 
(based on heat content measurement with $\pm 3 \%$ deviation)

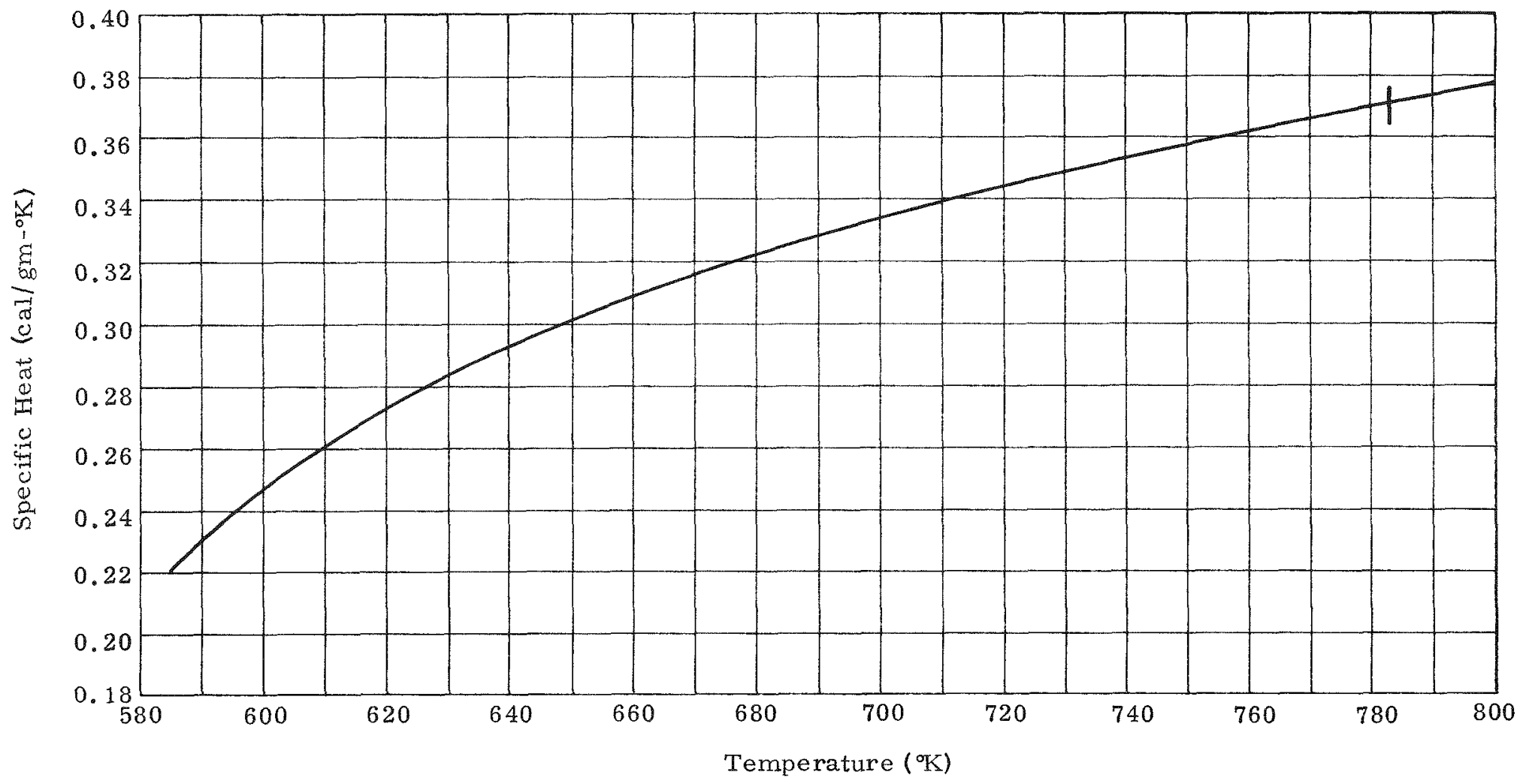

Fig. 14. Specific Heat, ZH62A Versus Temperature 


\section{Creep Measurements}

Creep properties at specimen temperatures of $583^{\circ}, 683^{\circ}$, and $783^{\circ} \mathrm{K}$ were measured using a Baldwin Lever creep testing machine (Fig. 15). This apparatus consists of a device for applying a load on the specimen, a furnace for maintaining the specimen at a precise elevated temperature and an extensometer with a recorder for measuring material deformation to an accuracy of $0.005 \mathrm{~mm}$.

After installing a specimen in the machine, the furnace was purged with argon, the temperature brought to the desired level and the load applied. The temperature of each specimen was monitored by an attached chromel-alumel thermocouple. Each specimen was tested under load for three hours or until a failure occurred, whichever came first. The results of these tests are listed in tabular form in Table 3.

\section{Tensile Properties}

Yield and ultimate strength, elongation and tensile modulus were obtained for this material at $295^{\circ}$ (room temperature), $583^{\circ}, 683^{\circ}$ and $783^{\circ} \mathrm{K}$. These tests were performed using a 2270-kilogram PTE Universal test machine with a Marshall furnace attached as shown in Fig. 16. A separable extensometer with recorder was used to measure changes in the specimen length. Specimen temperature was monitored by a chromel-alumel thermocouple fastened to each specimen.

Each specimen was mounted in the machine surrounded by, but not touching, the Marshall furnace. During the heating period, the furnace was continually purged with an inert argon gas in order to preclude oxidation of the material specimen. Three specimens at each temperature were tested. The results of these tests are listed in tabular form in Table 4.

\section{Thermal Expansion}

Measurements of the thermal expansion of this material were made at $100^{\circ} \mathrm{K}$ intervals from $383^{\circ}$ to $783^{\circ} \mathrm{K}$ using the quartz tube dilatometer shown in Fig. 17. Both dilatometer and specimen were placed in a Marshall furnace which was kept purged of air by argon gas to prevent oxidation of the test specimen. A chromel-alumel thermocouple embedded in the specimen was used to monitor its temperature. Figure 18 shows the results of this test. 


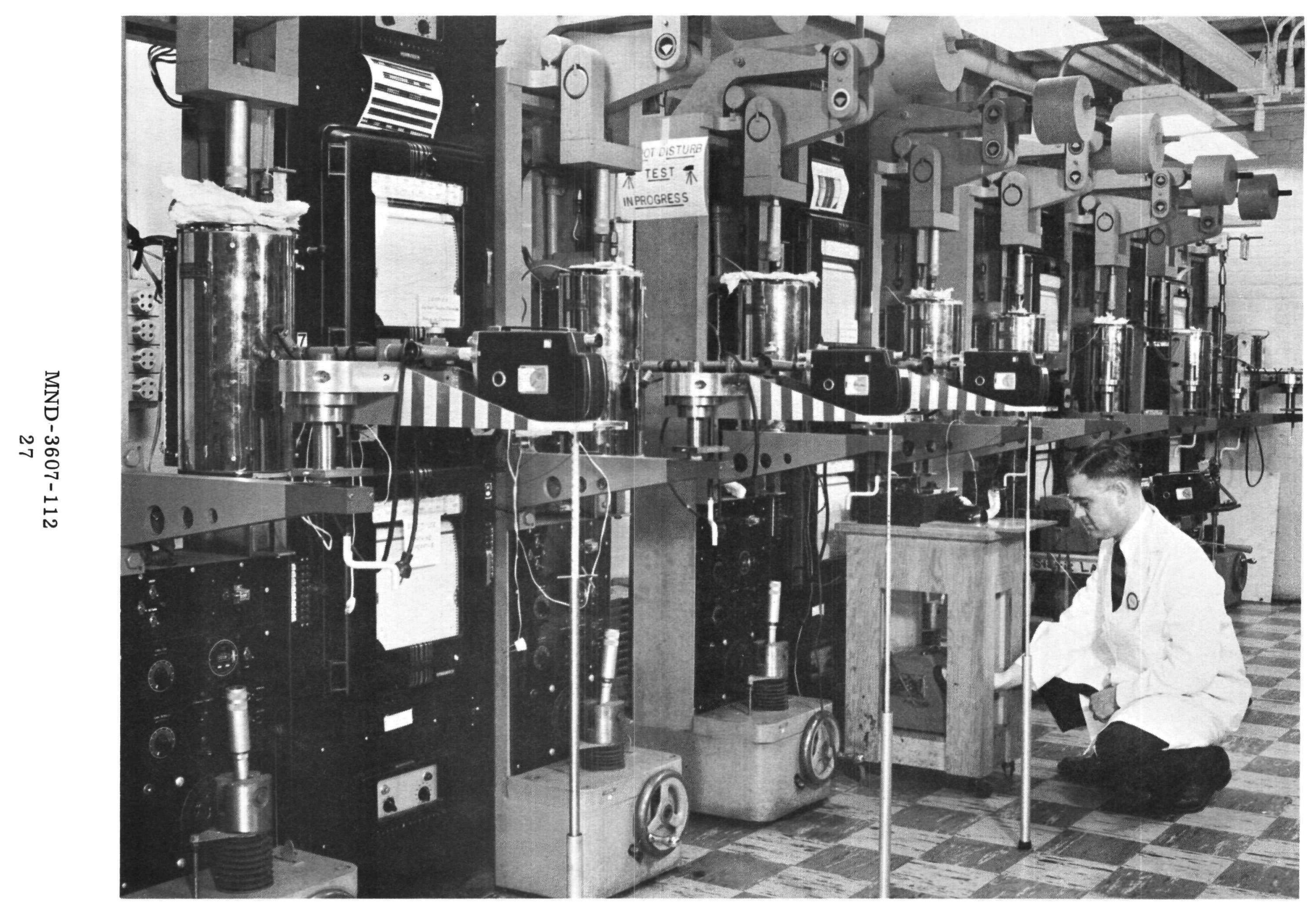

Fig. 15. Test Facility Used for Creep Measurements 


\section{TABLE 3}

Creep Test Results

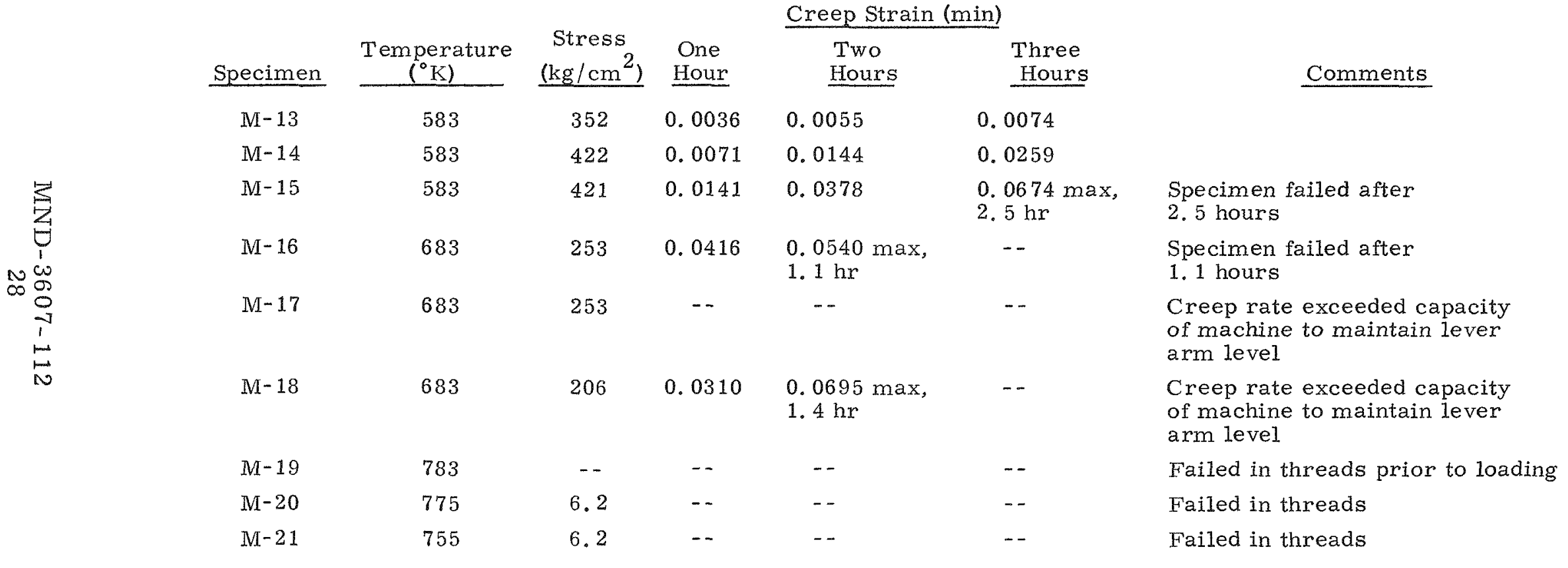




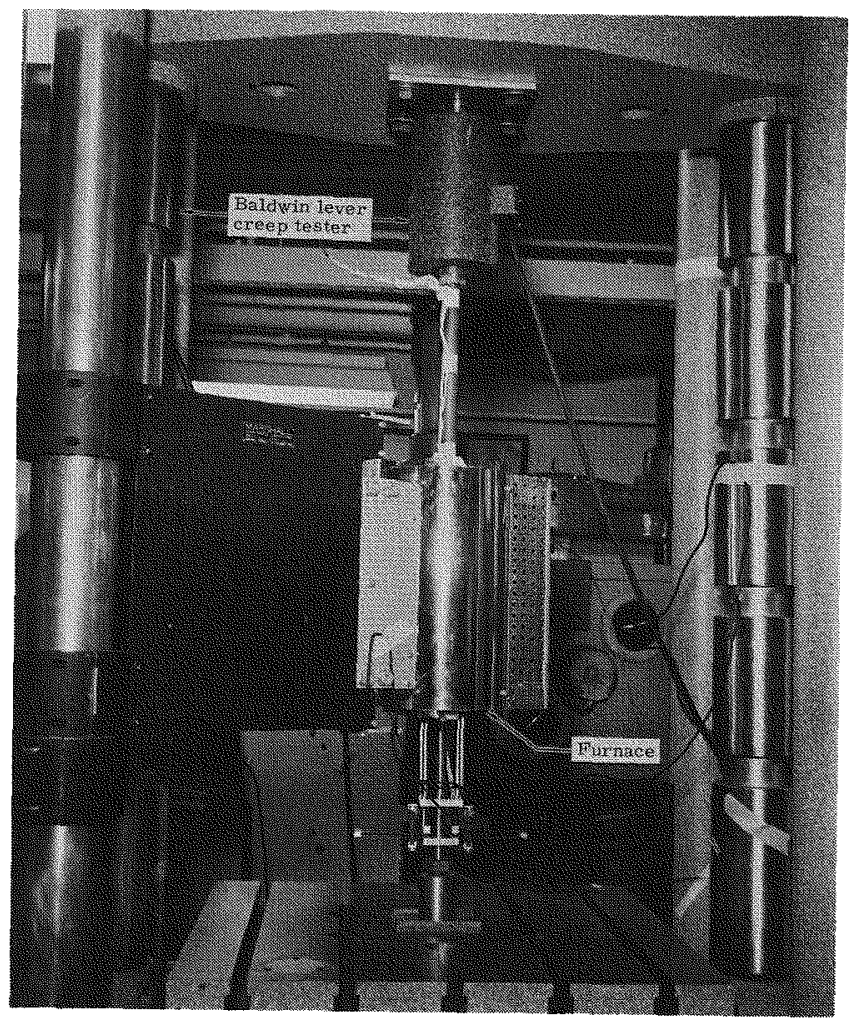

Fig. 16. Test Facility Used for Tensile Properties

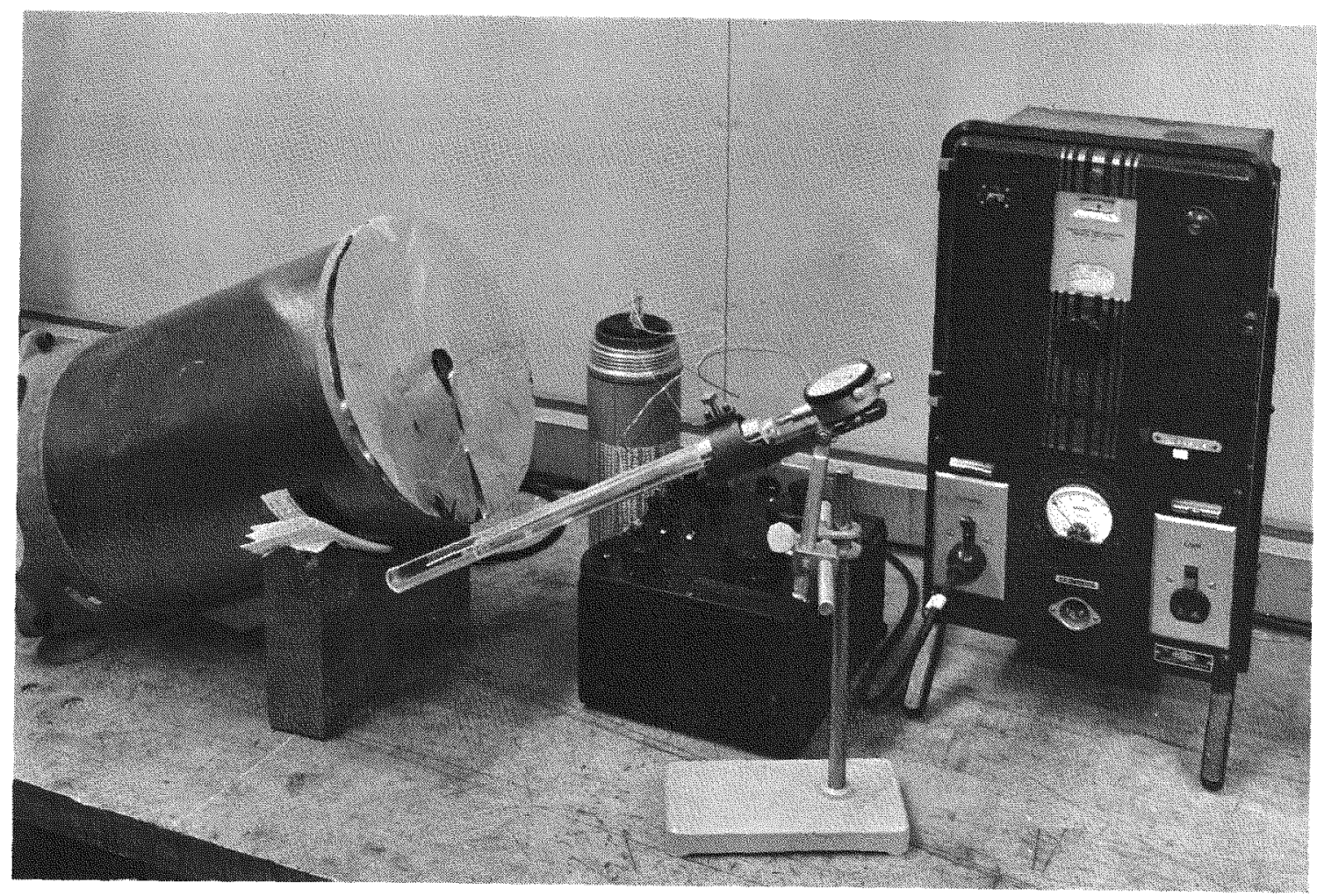

Fig. 17. Test Facility Used for Thermal Expansion Measurement 
TABLE 4

Summary of Tensile Test Data

Modulus

\begin{tabular}{|c|c|c|c|c|c|}
\hline $\begin{array}{c}\text { Sample } \\
\text { No. } \\
\end{array}$ & $\begin{array}{l}\text { Area } \\
(\text { in. } 2) \\
\end{array}$ & $\begin{array}{l}\text { Yield Stress } \\
\text { (psi) } \\
\end{array}$ & $\begin{array}{l}\text { Ultimate Stress } \\
\text { (psi) } \\
\end{array}$ & $\begin{array}{c}\text { Elongation } \\
(\%)\end{array}$ & $\begin{array}{l}\times 10^{-6} \\
\text { (psi) }\end{array}$ \\
\hline \multicolumn{6}{|c|}{ Room Temperature } \\
\hline$M-1$ & 0.2001 & 21,490 & 35,080 & 6.0 & 6.22 \\
\hline$M-2$ & 0.1999 & 22,010 & 37,120 & 7.0 & 6.04 \\
\hline$M-3$ & 0.2001 & 21,990 & 32,580 & 4.5 & 6.14 \\
\hline \multicolumn{6}{|c|}{ Temperature $583^{\circ} \mathrm{K}\left(589^{\circ} \mathrm{F}\right)$} \\
\hline$M-4$ & 0.2001 & 7,750 & 11,640 & 27.0 & 4.21 \\
\hline$M-5$ & 0.2001 & 7,900 & 11,120 & 38.0 & 4.16 \\
\hline$M-6$ & 0.2005 & 7,360 & 10,820 & 31.0 & 3.59 \\
\hline \multicolumn{6}{|c|}{ Temperature $683^{\circ} \mathrm{K}\left(769^{\circ} \mathrm{F}\right)$} \\
\hline$M-7$ & 0.1994 & 4,860 & 6,270 & 41.0 & 3.24 \\
\hline$M-8$ & 0.2001 & 4,750 & 5,470 & 21.0 & 2.69 \\
\hline$M-9$ & 0.2001 & 4,000 & 4,720 & -- & 2.94 \\
\hline \multicolumn{6}{|c|}{ Temperature $783^{\circ} \mathrm{K}\left(949^{\circ} \mathrm{F}\right)$} \\
\hline$M-10$ & 0.2001 & -- & 210 & -- & - - \\
\hline$M-11$ & 0.2001 & -- & 115 & -- & -- \\
\hline$M-12$ & 0.2001 & -- & 90 & -- & -- \\
\hline
\end{tabular}




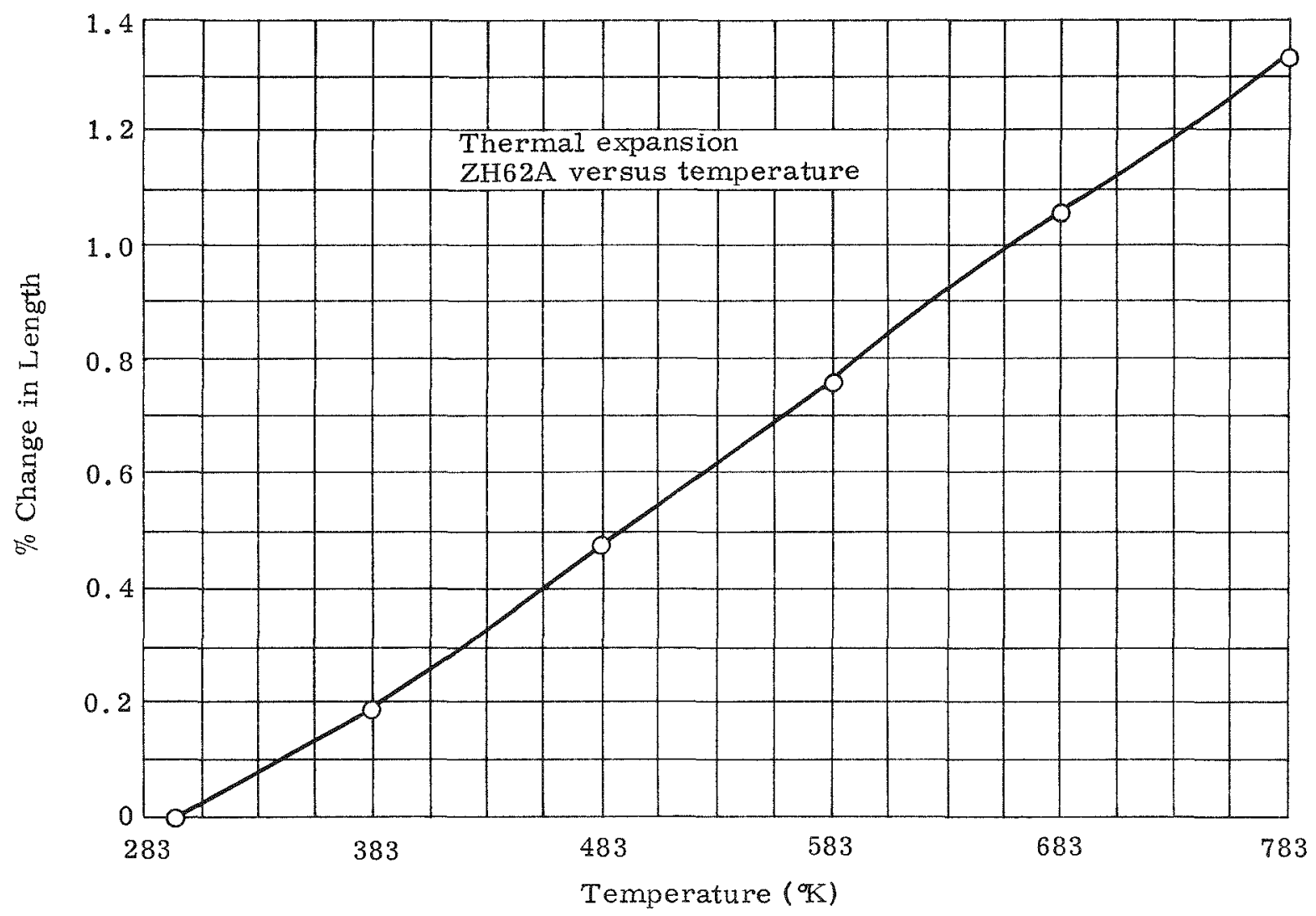

Fig. 18. Thermal Expansion, ZH62A Versus Temperature 
Blank 


\section{DISCUSSION OF RESULTS}

\section{A. JOINT THERMAL CONTACT CONDUCTANCE}

Theoretical analysis of microscopic contact conductance (Refs. 3, $8,9)$ indicated that under vacuum conditions conductance is directly proportional to the material conductivity and to the pressure applied to the contact surfaces, and inversely proportional to the micro hardness and surface roughness index. In analytical form, the microscopic contact thermal conductance may be expressed as (Ref. 2)

$$
h=\frac{2 K_{i j} P_{a}}{H a_{m i}}
$$

where $K_{i j}=2 K_{i} \times K_{j} /\left(K_{i}+K_{j}\right)$ is the combined thermal conductivity when heterogeneous materials are used such as in the case of three of the five specimens tested, $\mathrm{P}_{\mathrm{a}}$ is the contact pressure, $\mathrm{H}$ is the microhardness of the harder material and $\mathrm{a}_{\mathrm{mi}}$ the radius of each microscopic contact area which is assumed to be circular. Test results of all ungreased specimens show a rising thermal conductance with temperature. For Specimens 1, 2 and 3 which consisted of pairs with 2024-T4 Al contacting ZH62A Mg, and fastened by a steel bolt, this is most likely caused by an increase in contact pressure, $P_{a^{*}}$ This increase is due to the lower value of the coefficient of thermal expansion of the steel than those of the aluminum and magnesium alloys, since the combined conductivity of the magnesium and aluminum alloys does not vary much with temperature. For the two steel specimens fastened by steel bolts, the slight rise in conductance with temperature is probably due to the rising thermal conductivity, $K_{i j}$, of the material with temperature.

The top curve in Fig. 6 shows some peculiarity of reduced thermal conductance above $250^{\circ} \mathrm{F}$. The only explanation of this is that the four tests which resulted in this curve were conducted at the outset of the program, prior to gaining sufficient experience in extracting reliable data from the tests. It can be safely assumed that the trend of this curve would conform to those shown by the others. As a matter of fact, the same peculiar behavior was initially exhibited by the second curve from the top, but a later repetition of the test runs corrected this discrepancy.

The application of silicon grease to the contact joint increases the joint thermal conductance about six times, as indicated by comparison of Figs. 6 and 7. However, there is a consistent indication of a lower joint thermal conductance at $500^{\circ} \mathrm{F}$ as compared to that at lower temperatures. There is a possibility that partial evaporation of the grease 
under the combined effects of high temperature and low pressure is causing this phenomenon. It should be pointed out that in the case of the greased specimens, the mean temperature difference across the contact joint ranged from $0.4^{\circ}$ to $5^{\circ} \mathrm{F}$, with opposing individual thermocouples occasionally indicating an unexpected increase in temperature in the direction of the heat flow. Thus, the accuracy of the absolute values is highly dubious.

In the thermal scaling of contact thermal conductance of bolted joints, some encouraging results were obtained. According to Eq 16 of Ref. 1, the ratio of thermal conductances of two joints of identical geometry is given by

$$
\frac{h_{m}}{h_{p}}=\left(\frac{K_{m}}{K_{p}}\right)\left(\frac{P_{m}}{P_{p}}\right)\left(\frac{H_{p}}{H_{m}}\right)\left(\frac{a_{p}}{a_{m}}\right)
$$

where subscripts $m$ and $p$ denote properties associated with the model and the prototype, respectively. For parameters on the right side of the equation, $K$ and $H$ are properties of material, $a_{i}$ is a function of the machine finish and $P$ is a parameter that is controllable in operation. With $a_{p}$ and $a_{m}$ (Figs. 19 and 20) measured from precise profilometer readings and $\mathrm{H}_{\mathrm{p}}$ and $\mathrm{H}_{\mathrm{m}}$ (Table 5) as properties proportional to the ultimate strength converted from measured Rockwell hardnesses, the ratio of thermal conductances of Specimens 1 and 5 under vacuum condition is

$$
\begin{aligned}
\frac{h_{m}}{h_{p}}= & \left(\frac{P_{m}}{P_{p}}\right)\left(\frac{K_{m}}{K_{p}}\right)\left(\frac{H_{p}}{H_{m}}\right)\left(\frac{a_{p}}{a_{m}}\right)=1 \times \frac{135}{16} \times \frac{6150 \mathrm{~kg} / \mathrm{cm}^{2}}{3868 \mathrm{~kg} / \mathrm{cm}^{2}} \times \\
& \frac{5.33 \times 10^{-3} \mathrm{~mm}}{7.92 \times 10^{-3} \mathrm{~mm}}=9.03
\end{aligned}
$$

Experimental results indicated that the ratio is 8.2 at $610^{\circ} \mathrm{R}, 8.8$ at $710^{\circ} \mathrm{R}$ and 8.6 at $810^{\circ} \mathrm{R}$. The agreement is extremely close.

Thermal scaling on the effect of size was investigated using Specimens 4 and 5. Specimen 4 (SS-304) was made with approximately the same machine finish as Specimen 5 (SS-347), but only half scale in size. However, a larger surface waviness exists in Specimen 5 as identified by comparison of Figs. 20 and 21. Thus, the thermal conductances of these two have to be compared in a macroscopic way. Based on Eq 13 of Ref. 1, the ratio of macroscopic thermal conductance of the model and the prototype is 


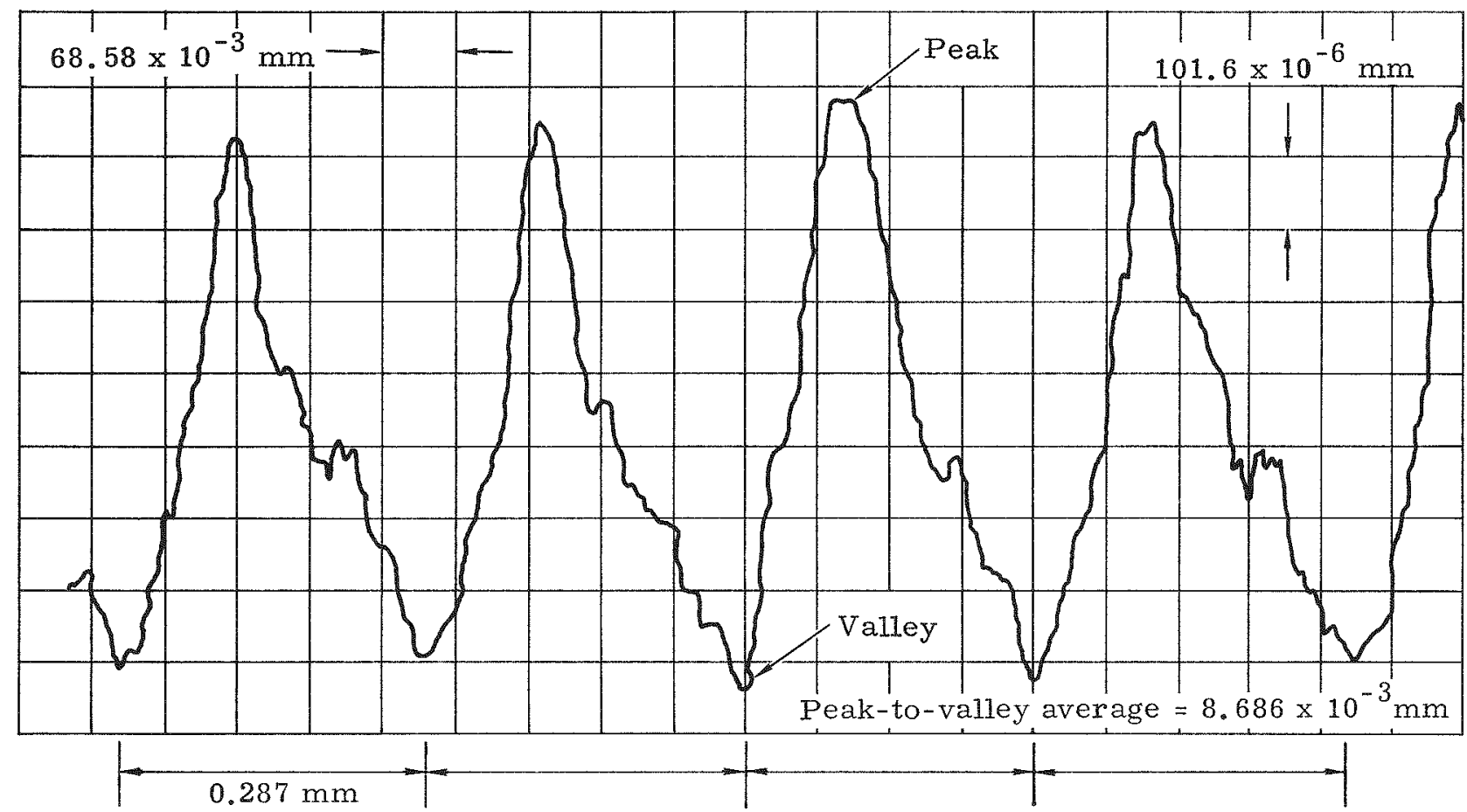

Fig. 19. Surface Profile, Specimen 1 


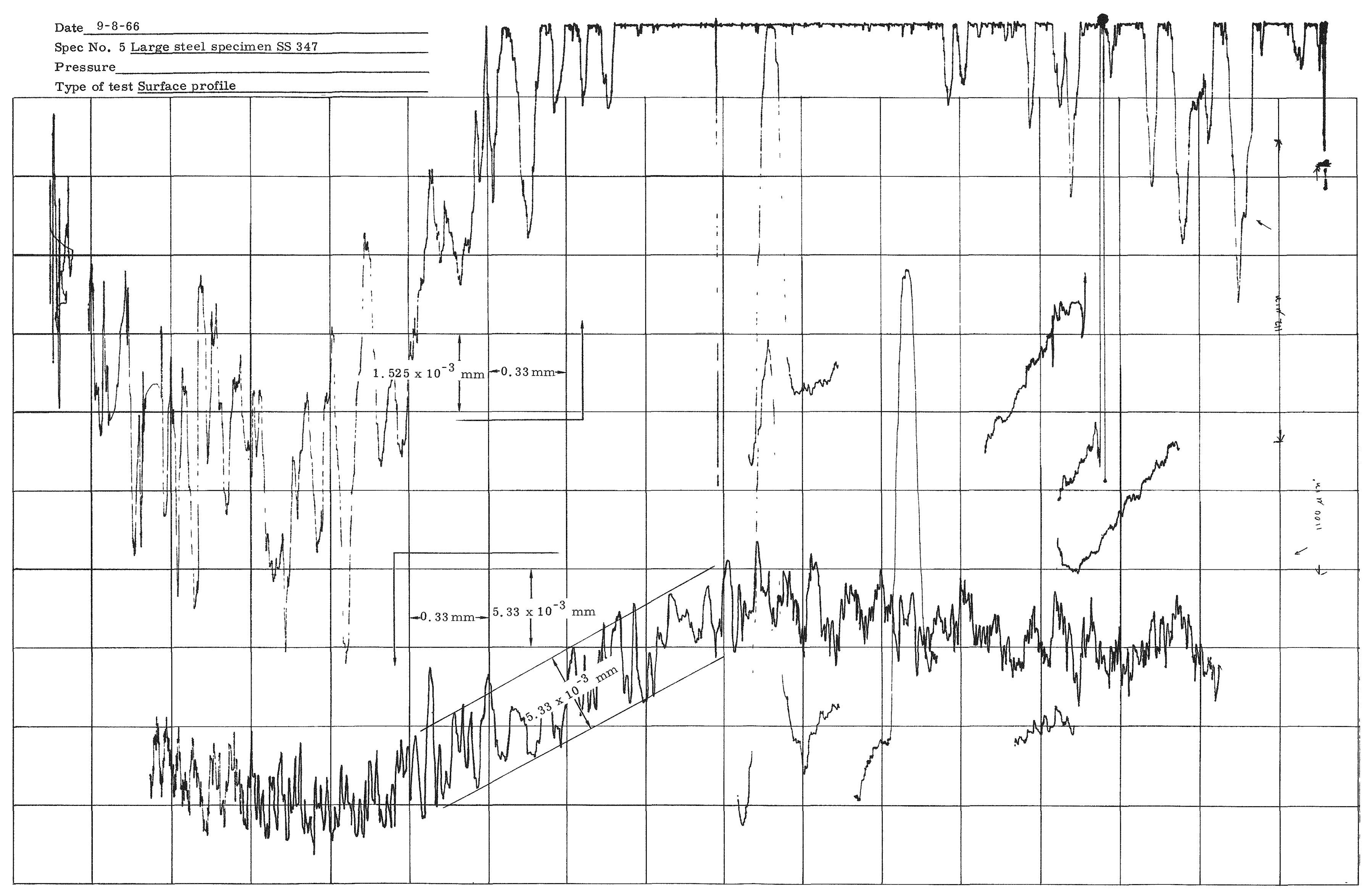


Date $\quad 9-9-66$

Spec No.

Type of test Surface Profile

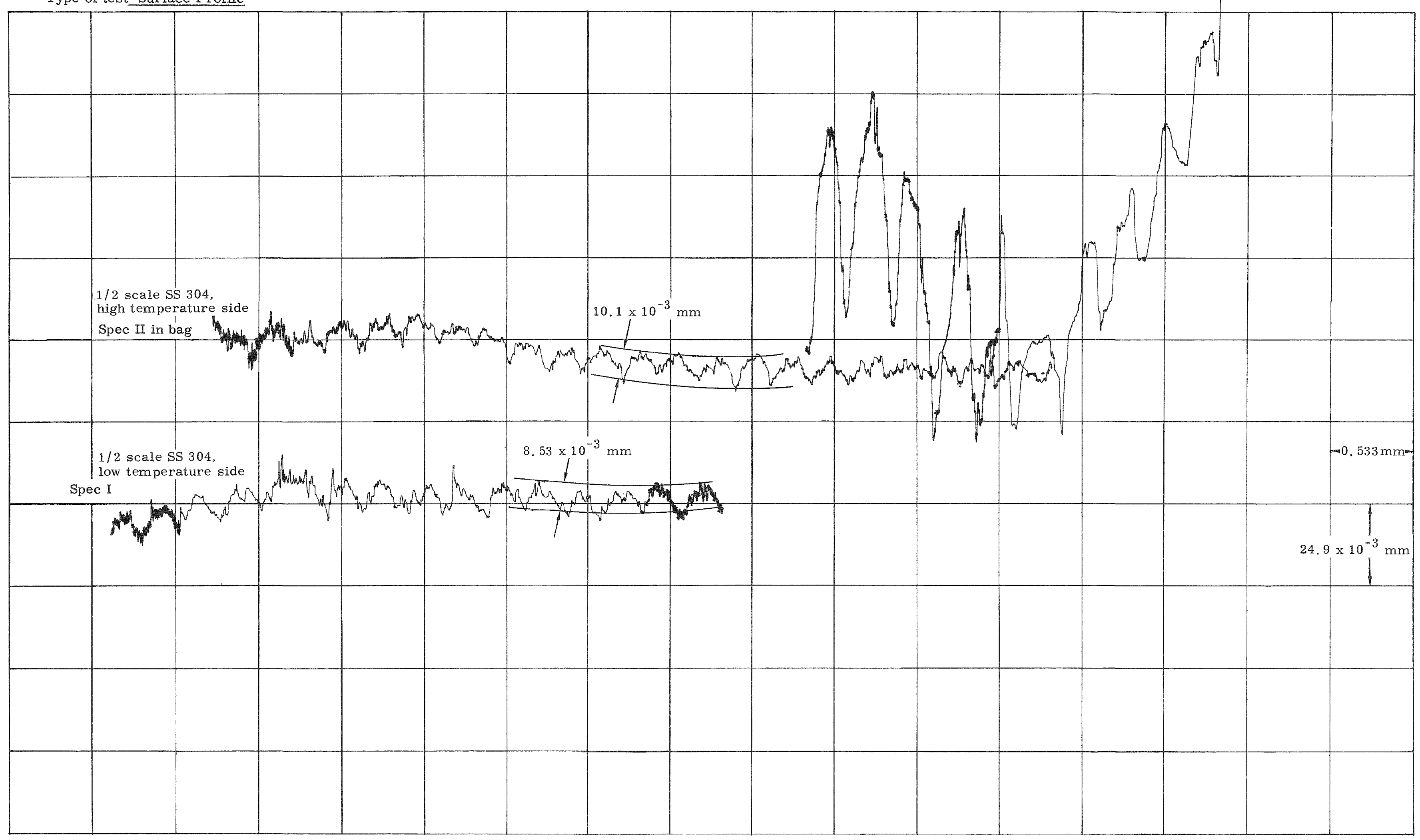

Fig. 21. Surface Profile, Specimen 4 


$$
\frac{h_{m}}{h_{p}}=\frac{K_{m}}{K_{p}} \times \frac{x_{m}}{X_{p}} \times \frac{b_{p}}{b_{m}} \times \frac{f\left(x_{p}\right)}{f\left(X_{m}\right)}
$$

where $b$ denotes the radius of macroscopic contact area and $X$ the $r$ atio of $r / b$ with $r$ the radius of the area where microscopic contacts exist, as shown in Fig. 22. Function $f(x)$ is given as

\section{TABLE 5}

Some Material Properties of Specimens

\begin{tabular}{|c|c|c|c|}
\hline Material & $\begin{array}{l}\text { Measured } \\
\text { Rockwell } \\
\text { Hardness }\end{array}$ & $\begin{array}{c}\text { Converted } \\
\text { Brinell } \\
\text { Hardness No. }\end{array}$ & $\begin{array}{c}\text { Converted } \\
\text { (approximate) } \\
\text { Ultimate Tensile } \\
\text { Strength }\left(\mathrm{kg} / \mathrm{cm}^{2}\right)\end{array}$ \\
\hline $\begin{array}{l}\mathrm{ZH} 62 \mathrm{~A} \\
\text { casting }\end{array}$ & $\begin{array}{l}100-\mathrm{kg} \text { load } \\
1 / 8-\mathrm{in} \text {. indenter } \\
\mathrm{E} 68 \text { to } 68.5 \\
\mathrm{~B} 20\end{array}$ & 58 & 2110 \\
\hline $\begin{array}{l}\text { Aluminum } \\
\text { fitting }\end{array}$ & $\begin{array}{l}\text { E96 } \\
\text { B65 }\end{array}$ & 105 & 3868 \\
\hline $\begin{array}{l}\text { Corrosion } \\
\text { resistant } \\
\text { steel fitting }\end{array}$ & $\begin{array}{l}\text { B79 } \\
1 / 16-\text { in. steel bar } \\
\text { indenter }\end{array}$ & - & $\begin{array}{l}5270 \text { to } \\
7000\end{array}$ \\
\hline
\end{tabular}

$$
f(X)=1-1.409 X+0.0959 X 3+\ldots \ldots
$$

Assuming the surface waviness to be of a sinusoidal nature as shown in Fig. 22, the elastic contact widths are calculated according to Hertz's theory as presented in Ref. 10. Thus,

$$
\frac{\mathrm{h}_{\mathrm{m}}}{\mathrm{h}_{\mathrm{p}}} \simeq\left|\times \frac{0.544 \mathrm{~mm} /(2 \times 1.981 \mathrm{~mm})}{0.328 \mathrm{~mm} /(2 \times 1.981 \mathrm{~mm})} \times\right| \times \frac{0.87}{0.79}=1.84
$$

Experimental results show a value of 2.39 . This discrepancy is attributed to the instrumentation difference. Due to the small size, only four thermocouples on each plane are installed on Specimen 4 near the central portion where the temperature drop across the contact surfaces is less; on the other four specimens, six thermocouples on two concentric circles were used. If the thermal conductance of Specimen 5 was calculated from the inner thermocouples only, the ratio so obtained would be 1.72 . 
According to Eq 17 of Ref. 2, in cases of mechanical joints with contact surfaces coated with vacuum heat transfer grease, the thermal resistance of the joint is given as

$$
R=\frac{1}{2 a_{s} K_{i g}}+\frac{1}{2 a_{s} K_{g j}}
$$

where $\mathrm{K}_{\text {ig }}$ denotes the combined thermal conductivity of surface $\mathrm{i}$ and the grease and $K_{g j}$ the thermal conductivity of the grease and surface $j$ of the joint. Since the grease separates the two surfaces completely, the macroscopic resistance no longer exists. With $K$ having a value of 0.126 watt $/ \mathrm{m}^{2}-\left({ }^{\circ} \mathrm{K} / \mathrm{m}\right)$ for the GE-683 grease, 16.1 for $\mathrm{SS}-304$ and SS-347 and 135 for 2024-T4, it is evident that the thermal resistance of all greased joints will be approximately the same regardless of the joint material or pressure since the thermal resistance offered by grease is so much higher compared to that due to the metals. As shown in Fig. 7, this fact is borne out by this program. The discrepancies of Specimen 1 from those of Specimens 3 and 4 are about $23 \%$. 
Specimen No. 4

$\mathrm{b} \simeq 1.981 \mathrm{~mm}$

$\mathrm{s} \simeq 0.00584 \mathrm{~mm}$

$r \simeq 0.544 \mathrm{~mm}$

$\mathrm{X}=0.137$
Specimen No. 5

$\mathrm{b} \simeq 1.981 \mathrm{~mm}$

$\mathrm{s} \simeq 0.00813 \mathrm{~mm}$

$r \simeq 0.328 \mathrm{~mm}$

$X=0.082$

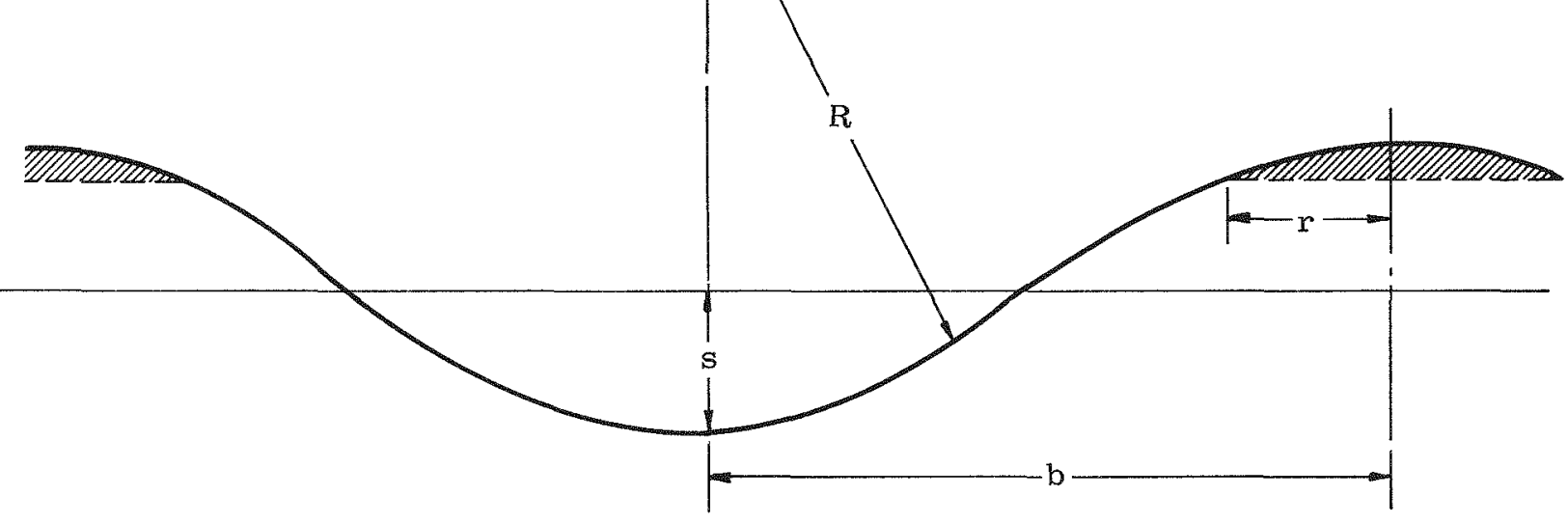

Fig. 22. Surface Geometry of Specimens 4 and 5

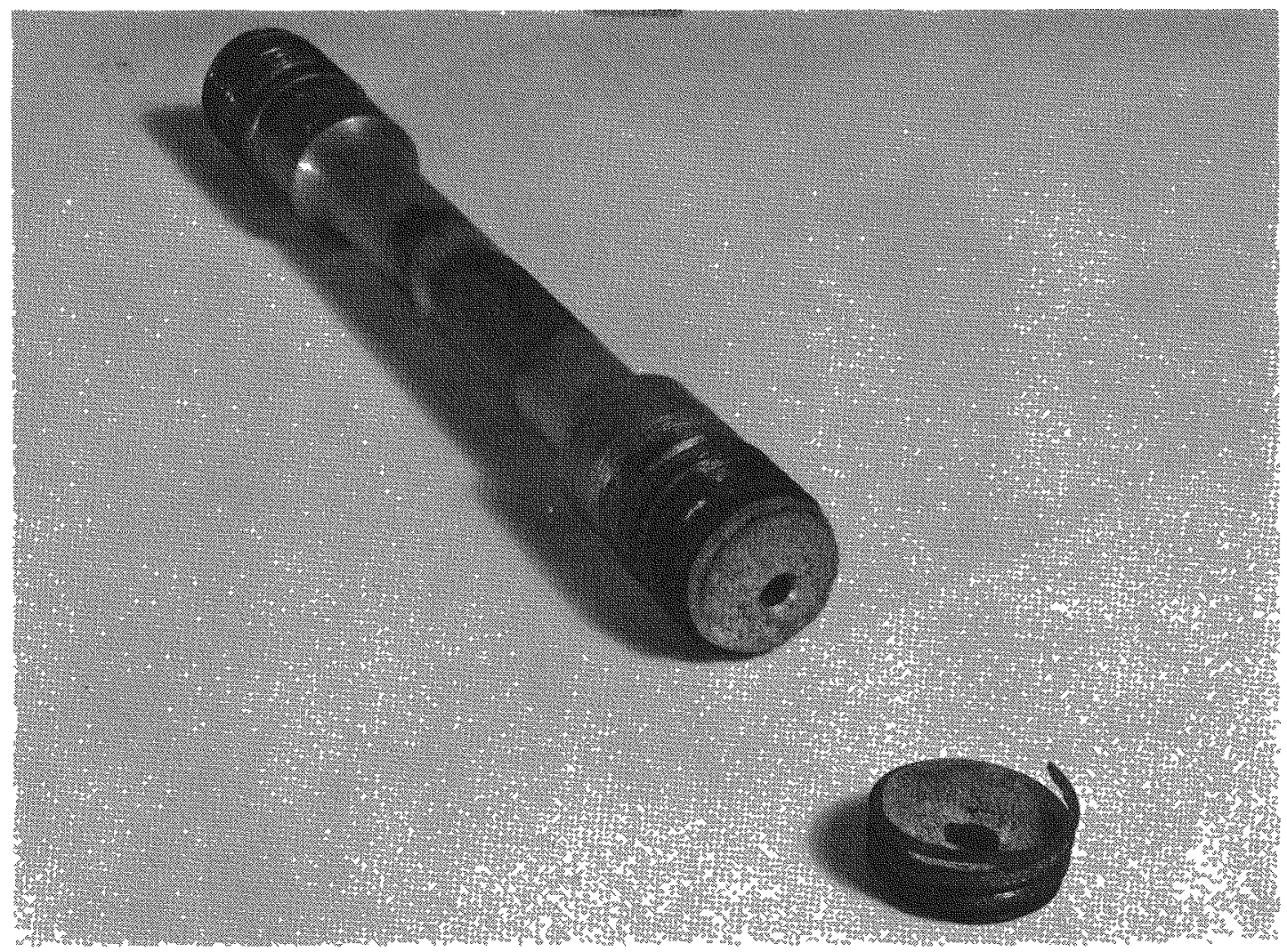

Fig. 23. Creep Test Specimen that Failed Before Load Application 


\section{B. MATERIAL PROPERTIES MEASUREMENTS}

Material properties measurements in this program are, in general, routine with the exception of the temperature range which extended into the region close to the melting point. Some difficulties were encountered in the thermal conductivity and creep strength measurements at these elevated temperatures.

Figure 12, thermal conductivity versus temperature of $\mathrm{ZH} 62 \mathrm{~A}$, shows the scattering of points at $500^{\circ} \mathrm{C}$ measured by a Martin cut bar calorimeter equipped with a guarded heater. Because of this wide scattering of data from the three specimens, some parallel experimental work was carried out in the Nuclear Research and the Thermodynamics Laboratories. All results are identified separately in Fig. 12. The dotted extension into the scattering region was drawn so it simulated the behavior of pure magnesium. It is of interest to know that the apparatus used in the Thermodynamics Laboratory was modified from the thermal conductance test apparatus to realize the desired confirmational points. However, a literature search established that the arrangement was one of the two methods recommended by the National Bureau of Standards.

On creep strength tests, it was found that at the highest temperature the specimen broke just as the load was being applied. The temperature was then reduced by an increment of $30^{\circ} \mathrm{K}$ for each of two additional tests, but the same phenomenon was repeated. Figure 23 shows one of the test specimen retrieved from the fixture. The fracture could have resulted from a number of causes, which included:

(1) Compression failure as a result of the difference of coefficient of expansion of the material and the threaded Inconel grip

(2) Weakening of the material at this temperature

(3) Local stress concentration due to oxidation.

Continued investigation of the cause of this failure was beyond the scope of this program and the matter was not solved. 
Blank 


\section{CONCLUSION AND RECOMMENDATIONS}

The joint thermal conductance test program was a success. Values of contact thermal conductance for three typical types of mechanical joints were obtained at four different temperatures ranging from $340^{\circ}$ to $590^{\circ} \mathrm{K}$. Joints were tested first with surfaces carefully cleaned and then again with surfaces coated with a special thermal grease similar to the type used on Nimbus B spacecraft. Except for tests with greased surfaces, scattering of experimental points from a smooth curve amounted to no more than $3 \%$. The results of the tests conducted on the three full-scale specimens are being used for thermal analysis of Nimbus B/SNAP 19.

Thermal scaling of bolted joints was also attempted in this program for application to thermal modeling experiment (SNAP 19 Experimental Safety Program Test $4(1)(a))$. Thermal scaling applied to materials of different properties deviated from Shih's scaling law (Ref. 1) for joints with identical surface geometry by less than $11 \%$ at all temperatures. Thermal scaling applied to size variation was equally successful, if proper correction is taken for the difference in instrumentation of the two specimens used. Otherwise a deviation of $30 \%$ from Shih's scaling law for joints in which macroscopic thermal restriction dominates can be encountered. For joints with contact surfaces separated by a thermal grease, it was found that the thermal conductance of all joints tested increased sixfold or more over clean surfaces and that the contact conductance is insensitive to the type of fastening, the materials forming the joint or the size of the joint. The results seem to agree well with Shih's hypothesis on greased joints in Ref. 1.

Materials properties measured at room temperatures were in general agreement with literature values. The validity of values at higher temperatures can only be judged by the trend of the property versus temperature curve and the scattering of the test points. There are two events worth mentioning. On thermal conductivity of ZH62A at temperature above $673^{\circ} \mathrm{K}$, supplementary tests had to be carried out at two other laboratories to establish the trend of the curve. How ever, the accuracy of those points above $673^{\circ} \mathrm{K}$ is questionable. Values should be used with caution. On creep strength at high temperature $\left(775^{\circ}\right.$ to $\left.783^{\circ} \mathrm{K}\right)$, the specimens broke before applying the load. The cause of the failure was not identified.

\section{A. RECOMMENDATIONS}

It is highly recommended that some followup work be conducted to ascertain additional useful data which would be beneficial to both the 
SNAP 19 program and future programs involving magnesium alloys and mechanical joints.

More material creep tests should be conducted at higher temperature ranges to determine the cause of failure of three specimens tested between $755^{\circ}$ to $787^{\circ} \mathrm{K}$. A new type of grip should be used to avoid compression stress developed due to differences in thermal expansion of the materials of the specimens and fixture or the thread on the grip may be relieved to eliminate such interference. Better environmental control of the test chamber should be provided to avoid reaction stress concentration.

Two different sizes of specimens should be used to check the effect of the environment on size. A total of 12 tests should be conducted.

Additional test runs should be conducted on mechnical joint Specimens 1,4 and 5 with and without heat transfer grease between the contact surfaces. A few of the early runs in this program should be repeated to check the validity. More runs should be made to check the effect of contact pressure on thermal conductance. The pressure effect was not investigated in this program because it was originally aimed specifically for application to the particular design.

Two three-bolt specimens should be fabricated and tested to investigate the restraining effect of neighboring bolts on the thermal conductance of a bolted joint. 


\section{REFERENCES}

1. Shih, C., "Thermal Similitude of Manned Spacecraft." AIAA Paper 66-22.

2. Gabron, F., Johnson, R. W., Vickers, J. M. F., and Lucas, J. W., "Thermal Scale Modeling of the Mariner IV Spacecraft." AIAA Paper 66-22.

3. Clausing, A. M. and Chao, B. T., "Thermal Contact Resistance in a Vacuum Environment." ME-TN-242-1 Engineering Experiment Station, University of Illinois.

4. Hultberg, J. A., "Thermal Joint Conductance." Personal correspondence.

5. Timoshenko, S., Strength of Materials, Part II; Advanced Theory and Problems. D. Van Nostrand Company, Inc., 1941.

6. Aron, W. and Colombo, G., "Controlling Factors of Thermal Conductance Across Bolted Joints in a Vacuum Environment.' ASME Paper 63-WA-196.

7. Elliott, D. H., "Thermal Conduction Across Aluminum Bolted Joints." ASME Paper 65-HT-53.

8. Fenech, H., Henry, J. J., and Rohsenow, W. M. , Thermal Contact Resistance. Chapter 13, "Development in Heat Transfer." MIT Press, 1964.

9. Shlykov, Yu. P. and Ganin, Ye. A., "Thermal Resistance of Metallic Contacts." Journal of Heat Mass Transfer, Vol 7, pp 921 to 929.

10. Roark, R. J., Formulae for Stress and Strain. McGraw-Hill Book Company, 3rd edition. 